\title{
EL DERECHO DE LOS CURSOS DE AGUA INTERNACIONALES*
}

\section{La problemática en el Derecho Internacional}

Los ríos, han desempeñado un papel preponderante en la vida económica, social y política de pueblos y continentes. Así, un autor de mediados del siglo XIX sostenía: "En el origen de las sociedades, los hombres han debido fijar sus habitaciones en los sitios en que la naturaleza les ofrecía las aguas necesarias a sus menesteres. Las localidades que carecían de aquellas han estado privadas de habitantes, o al menos, las poblaciones que las frecuentaban se limitaban a hacer de ellas una morada más o menos temporal \{...\} A medida que los hombres se fueron multiplicando, se reunieron en sociedad, las colocaron a las orillas o a las proximidades de los ríos o de manantiales bastante abundantes para proveer á sus necesidades. El arte de conducir las aguas debió nacer y perfeccionarse con bastante prontitud, para permitir más libertad en elegir la situación de las ciudades" 1 .

En los siglos de la colonización, las grandes vías fluviales constituyeron irremplazables caminos para penetrar hasta regiones que de ningún otro modo hubiera sido posible acceder en la época. La navegación fluvial, permitió a españoles y portugueses acelerar -a través del Plata, Amazonas ${ }^{2}$ y Orinoco-, el proceso de expansión territorial que comenzó en el siglo XVI y prosiguió por espacio de casi tres centurias. También, las potencias colonizadoras europeas, en el siglo XIX, encontrarían adecuados medios de penetración hacia el centro del continente en las vastas redes fluviales de África, y la ocupación de los vastos territorios y la determinación de áreas de influencia, habrían de incidir sobre el régimen jurídico internacional de sus principales ríos.

La existencia de los llamados ejes fluviales ha constituido un elemento propicio para la formación y desarrollo de los Estados. Los pueblos establecidos aguas abajo han manifestado permanentemente su preocupación por el uso que de las aguas hicieron sus vecinos de aguas arriba, circunstancia que con frecuencia, incidió en la determinación del régimen jurídico de la red fluvial.

El objeto de este estudio, está limitado fundamentalmente a los llamados ríos internacionales y a los que en años recientes se han denominado cursos de agua internacionales y su regulación jurídica, por lo que se excluye en principio, la consideración de aquellas vías fluviales que

\footnotetext{
*Este capítulo fue redactado por el Dr. Ernesto J. Rey Caro. Doctor en Derecho y Ciencias Sociales. Profesor Emérito de la Universidad Nacional de Córdoba. Su contenido es parte del trabajo El derecho de los cursos de agua internacionales. Publicado en Cours Euro - Mediterranéens Bancaja de Droit International. Volumen VII. 2003, y actualizado en algunos puntos.

${ }^{1}$ CALVO Y PEREYRA, M. De las aguas tratadas desde el punto de vista legal, Madrid, 1862 , pág. 2-3.

2 ALVARADO GARAICOA, T. La trascendencia del descubrimiento del Río de las Amazonas, en Estudios de Derecho Internacional Público y Privado - Homenaje al Prof. Luis Sela Sampil, Oviedo, España, T. 1, pág. 209-215.
} 
nacen, discurren y mueren en un mismo Estado, vías éstas que se encuentran sometidas a un régimen jurídico diferente y en torno a los cuales la problemática también ofrece sus peculiaridades. Ello no obsta a que ciertos ríos nacionales puedan quedar comprendidos, en un sentido amplio, en un sistema internacional.

No siempre las cuestiones que actualmente preocupan a gobernantes y juristas en relación al uso y aprovechamiento de los ríos internacionales, mostraron una misma dimensión, especialmente durante el medioevo y los primeros siglos de la Edad Moderna. En efecto, el uso navegación, como lo señaláramos constituyó durante muchos años el centro de la disputa jurídicopolítica, contraponiendo el derecho de soberanía de los estados ribereños con el derecho a la libre navegación que reclamaban los terceros estados. Ello explica, en particular desde el siglo XIX, la preocupación de los gobiernos por la adopción de normas expresas en orden a regular la navegación en las principales vías fluviales internacionales. Cabe señalar que la sanción unilateral de disposiciones consagratorias de la libertad de navegación en ciertos ríos internacionales no fue ajena a la obtención de algunas ventajas de carácter político o económico.

Siendo la navegación, por lo tanto, el uso principal de los ríos internacionales en los siglos anteriores, no fue extraño que las primeras formulaciones jurídico-internacionales estuvieran dirigidas a regular sus diversos aspectos.

No obstante, el Derecho Internacional fluvial clásico, habría de sufrir una profunda alteración con motivo de los grandes progresos tecnológicos que caracterizaron al siglo $\mathrm{XX}$ y que se proyectan, sin poder prever sus límites, a la actual centuria. Además de la navegación y la pesca, los ríos internacionales proporcionan una valiosa infraestructura para su explotación a mayor escala con fines agrícolas e industriales. Hoy se cuenta con medios técnicos adecuados para realizar obras de regadío y para el aprovechamiento hidroeléctrico de los cursos de los ríos, constituyendo un factor de relevancia en el desarrollo económico de los pueblos.

Los nuevos usos, consecuentemente, generaron nuevos problemas entre los Estados beneficiados por una misma red fluvial, surgiendo la necesidad de formular nuevas normas y principios jurídicos que ampliarían el marco tradicional del Derecho Internacional fluvial. Parte de esta tarea la desempeñaría y aún la cumple, el legislador internacional. Pero éste, si desea elaborar normas acordes con la realidad fáctica, deberá valerse de especialistas cuya actividad trasciende el campo estrictamente jurídico, como ingenieros, hidrólogos, geólogos, economistas, sociólogos, ambientalistas, entre otros.

Debe destacar, asimismo, que muchos factores, entre ellos los de índole político, económico, geográfico y social, han incidido en la relativa ausencia de reglas de Derecho internacional común, ya que cada río - o cada red fluvial-, ha sido considerado como una entidad particular, regida por principios jurídicos que, en muchos casos, no son aplicables a otras unidades 
fluviales. Ello explica también que los intentos de establecer una legislación uniforme a nivel convencional, hayan tropezado con múltiples dificultades.

\section{Concepto y cuestión terminológica}

Como lo anticipáramos, tanto en la doctrina como en la práctica, sea a nivel interestatal o en las organizaciones internacionales, se ha manifestado una tendencia a utilizar la expresión derecho de los cursos de agua internacionales para tipificar el conjunto de normas jurídicas aplicables en la materia, desplazando al clásico Derecho Internacional fluvial. No obstante, aún existen discrepancias en cuanto al alcance de la expresión cursos de agua internacionales. En la doctrina tradicional prácticamente no se establecía ninguna distinción entre este último concepto y el de ríos internacionales.

Diez de Velasco, ofrece un esquema de las distintas opciones al respecto. Según una de ellas, el concepto de curso de agua internacional se apoyaría en la noción de ríos internacionales elaborada en el Acta Final del Congreso de Viena de 1815, que toma como base para la reglamentación jurídico-internacional del uso de las aguas, la existencia de fronteras políticas por las que sus aguas corren o dividen el curso del río. En una segunda concepción, la expresión mencionada se basaría en la llamada cuenca fluvial, que comprendería a los ríos internacionales y a los afluentes de éstos aun cuando discurrieran de un solo Estado. Finalmente, hay quienes utilizan la expresión curso de agua internacional para referirse a las cuencas hidrográficas, cuencas hidrológicas o cuencas de drenaje, que comprenderían las aguas superficiales y subterráneas que fluyen a una salida común. En esta tercera opción, lo determinante para la regulación jurídica del uso de las aguas, no serían ya las fronteras políticas que las dividen, sino la unidad especial y funcional de tales aguas. Según el publicista español, esta última sería la posición más aceptable ${ }^{3}$.

La Comisión de Derecho Internacional en su momento, formalizó el estudio de la temática adoptando la expresión Derecho de los usos de los cursos de agua internacionales, dejando de lado, ab initio, algunas cuestiones comprendidas en la problemática, como la cuestión de la delimitación de dichos cursos de agua entre los Estados ribereños. Asimismo, cabría otra observación. La expresión Derecho de los cursos de agua internacionales podría en sentido amplio comprender tanto la normatividad interna o nacional como la internacional propiamente dicha, pues el Estado ribereño puede y de hecho lo hace, dictar normas para ser aplicadas en la parte del curso de agua internacional que discurre por su territorio. Igualmente, podría la problemática comprenderse en la expresión Derecho internacional de los cursos de agua compartidos entre Estados, pues en definitiva se trata, según algunos autores, de una categoría de los

3 DiEZ DE VELASCO VALlEJO, MANUEL. Instituciones de Derecho Internacional

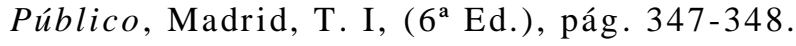


recursos naturales compartidos ${ }^{4}$, aun cuando no se puede desconocer la pertinencia de las objeciones que se han formulado a la expresión compartidos.

Ahora bien, más allá de la cuestión terminológica, surge el interrogante en torno a cuál sería el ámbito material de aplicación de esta rama del Derecho internacional. En un sentido amplio, comprendería los ríos internacionales, cuencas fluviales, cuencas hidrológicas o cuencas de drenaje y aún los canales y lagos situados en el territorio de dos o más Estados, pese a que no siempre los lagos pueden considerarse con propiedad un curso de agua. Por otra parte, los afluentes nacionales de un río internacional sólo por extensión y dentro de una concepción evolucionada e integral del sistema fluvial, podrían ser abarcados. Cabría también la posibilidad de que la materia en examen pudiera quedar comprendida en un llamado Derecho internacional de las aguas no marítimas compartidas entre Estados, pero también esta propuesta podría ser objeto de críticas y objeciones razonables.

Las reflexiones precedentes trasuntan las dificultades casi insalvables que se deben afrontar para encontrar una definición precisa y en su caso, determinar con cierta exactitud el contenido de este capítulo del Derecho internacional. Ello explica que en los estudios de la Comisión de Derecho Internacional, los relatores especiales aconsejaron postergar la cuestión terminológica stricto sensu, hasta el final de las discusiones, para evitar el estancamiento de los trabajos ${ }^{5}$. En otra parte de esta exposición, volveremos sobre este tema.

De allí que nos veamos constreñidos a utilizar una terminología variopinta, que en muchos casos estará determinada por las expresiones empleadas por los tratadistas, y por los conceptos recogidos en los instrumentos y documentos internacionales.

Se ha definido a un río, como la corriente continua que se origina en la tierra y fluye por su superficie, impulsada por la gravedad hasta desembocar en otro río, en un lago o en el mar 6 . Este concepto es común a los ríos nacionales y a los internacionales. En consecuencia, ¿cuál es el criterio que permite establecer una diferencia entre ambos? Son nacionales aquellos ríos que desde su nacimiento hasta su desembocadura discurren por el territorio de un sólo Estado. No se discute que el Estado ejerce sobre estos ríos la soberanía exclusiva, pudiendo, en consecuencia, excluir de su utilización a los otros Estados. En principio, esta categoría de ríos no tendría relevancia internacional. Sin embargo, como se verá oportunamente, no han faltado concepciones que pretendieron atribuir a ciertos ríos

\footnotetext{
${ }^{4}$ BARBERIS, JULIO. Los recursos naturales compartidos entre Estados y el Derecho Internacional, Madrid, 1979, pág. 143-144.

5 REY CARO, ERNESTO J. El derecho de los usos de los cursos de agua internacionales en los trabajos de la Comisión de Derecho Internacional, en Revista Española de Derecho Internacional, Vol. XXXI, No 1-3, 1978, pág. 39-64.

${ }^{6}$ AZCÁRRAGA, J. L. DE. Derecho Internacional Marítimo, Barcelona, 1970, pág 53.
} 
nacionales un status jurídico especial que los sustraían de la condición jurídica señalada.

En cuanto a los ríos internacionales, en general se ha tenido por tales a aquellos que atraviesan o separan el territorio de dos o más Estados, comprendiendo los ríos contiguos o fronterizos y los ríos sucesivos ${ }^{7}$. Algunos tratadistas, sin dejar de reconocer esta característica física esencial de los ríos internacionales, agregan otros caracteres. Otro problema de relevancia, relacionado con el concepto de río internacional, consiste en establecer si para un uso determinado, dicho concepto comprende nada más que el curso de agua principal, o bien, con un criterio más amplio, incluye también los afluentes que desembocan en él.

Generalmente, en cuanto a la navegación, sólo se ha reconocido a los afluentes con un carácter muy limitado y en razón de que el afluente, en ciertos casos, posee mayor importancia que el curso principal. La Corte Permanente de Justicia Internacional, en el caso relativo a la jurisdicción territorial de la Comisión Internacional del Oder, admitió la tesis -sostenida por Alemania, Dinamarca, Francia, Gran Bretaña, Suecia y Checoslovaquiade que la expresión río internacional, se aplicaba a todo el sistema fluvial, comprendiendo aún los afluentes exclusivamente nacionales ${ }^{8}$.

Pese al propósito de calificar los ríos internacionales por las circunstancias de hecho que determinan su utilización, la doctrina predominante distingue entre las dos clásicas categorías: los ríos contiguos o llamados también fronterizos -en razón de que sirven de límite entre dos o más Estados- y los ríos sucesivos que, desde su nacimiento hasta la desembocadura, discurren por varios Estados. En los hechos, existen ríos que reúnen ambas características.

A partir de la Convención de Barcelona de 1921, sobre el régimen de las vías navegables de importancia o interés internacional, surgió otra distinción. Conforme al artículo $1^{\circ}$ de la Convención, son vías navegables de interés internacional toda vía de agua que en su curso, naturalmente navegable desde y hacia el mar, divida o atraviese varios Estados y las vías de agua, o secciones de vías de agua naturales o artificiales que hayan sido expresamente colocadas bajo el régimen de la Convención citada, ya sea por actos unilaterales de los Estados bajo cuya soberanía se encuentran o en virtud de convenios suscritos con el consentimiento de dichos Estados. Esta última categoría ha dado origen a lo que parte de la doctrina ha calificado como ríos internacionalizados.

Una cuestión anexa a los ríos internacionales, es la de la delimitación. Tratándose de ríos sucesivos, el problema no es mayor y teóricamente el límite de separación de cada tramo estará determinado por la línea que une dos puntos de intersección de las orillas del río en la línea de la frontera de los Estados.

\footnotetext{
7 OPPENHEIM, M. A. Tratado de Derecho Internacional Público, Trad. de López Olivan, Barcelona, 1961, T. I, Vol. II, pág. 18.

${ }^{8}$ CPJI. Serie A, N²3, pág. 23.
} 
Para Rousseau, los límites fluviales, visibles y relativamente estables representan un tipo de frontera particularmente elegida por su precisión y fijeza, habiendo adquirido una gran importancia en la determinación de las líneas de separación política cuando tuvieron que resolverse las cuestiones fronterizas en no pocos países del continente europeo, africano, asiático y americano. Tal es el caso entre otros de los ríos Rhin, Danubio, Elba, Oder, Drave, Doubs, Lys y Guadiana en Europa; el Congo, el Níger, el río Muni, el Oned Draa y el Zambeze en África; el Chatt el Arab, el Jordán, el Nirmand, el Mekong y el Amour en Asia y el San Lorenzo, el Columbia, el Río Grande, el Orinoco, el Paraguay, el Paraná y el Río de la Plata, en América9

Como lo anticipáramos, la utilización de las aguas de los ríos internacionales ha dado origen a situaciones que deben ser tratadas individualmente. La navegación por los ríos internacionales genera problemas particulares que difieren de los originados en el uso a los fines de la pesca, del riego o de la explotación industrial, entre otros. Por otra parte, la creciente contaminación de las aguas, que impide su uso para ciertos fines, ha sido objeto en los últimos tiempos de gran preocupación, reflejada en la elaboración de normas tendentes a evitarla y subsidiariamente, a reparar los perjuicios por ella ocasionados.

\section{La navegación en los ríos internacionales}

\section{La libertad de navegación}

Un primer paso hacia la consagración del principio de la libertad de tránsito, se dio en el Congreso de Raestad, en 1804, cuando se abolieron los impuestos sobre el Rhin ${ }^{10}$. Diez años después, en el Congreso de París, de 1814, se declaró que la navegación por el Rhin debía ser libre a todas las naciones, dejando para el futuro congreso, las medidas a adoptarse para hacer efectivo este principio y la reglamentación respectiva.

Un hito importante fue el Congreso de Viena de 1815, que elaboró un Reglamento General relativo a la navegación fluvial, que ha sido calificado como la Constitución del derecho fluvial europeo. Conforme al artículo 108 del Acta General de Viena, los Estados cuyos territorios se hallaban separados o atravesados por un mismo río navegable, se obligaban a regular de común acuerdo todo lo relativo a la navegación de tal río. ,

Otro aspecto importante en los principios consagrados en el Congreso de Viena, es la extensión del principio de libertad de navegación a los brazos y afluentes de los ríos principales, que en su curso navegable separaban o atravesaban diferentes Estados (art. 110).

Tales principios debían ser puestos en práctica con respecto a ríos determinados, mediante la celebración de acuerdos particulares o especiales.

\footnotetext{
${ }^{9}$ ROUSSEAU. Droit International Public, París, 1977, T. III, pág. 252-257. E1 jurista francés ofrece una amplia casuística relacionada con los diversos sistemas de determinación de los límites fluviales.

${ }^{10}$ COLOMBOS J. Derecho Internacional Marítimo, Madrid, 1961 pág. 157.
} 
De allí la denominación de ríos convencionales otorgada a las vías fluviales cuyo régimen se reguló conforme a las estipulaciones contenidas en el Acta del Congreso de Viena.

El principio de la libertad de navegación, con las limitaciones expresadas, fue nuevamente consagrado en el Tratado de París de 1856, que extendió el régimen al río Danubio y creó una Comisión Permanente encargada de regular la navegación por el mismo.

Toda esta elaboración convencional, habría de tener repercusión a partir de la mitad de ese siglo en los territorios africanos colonizados. En efecto, en el Acta de Berlín de 1885, se extendió el régimen de internacionalización a los ríos Níger y Congo, emitiéndose una Declaración relativa a la libertad de comercio en la cuenca del Congo y sus desembocaduras y adoptándose el Acta de Navegación, que regulaba el régimen de navegación y de libertad de comercio en este río africano.

Pese a haberse sostenido que el Acta de Viena significó la consagración del principio de la libertad de navegación por los ríos internacionales de Europa tanto para los ribereños como para las demás naciones ${ }^{11}(51)$, se ha puesto en duda si los principios allí proclamados fueron verdadera y ampliamente aplicados en la realidad y si efectivamente alcanzaron una aplicación universal ${ }^{12}$.

Después de la Primera Gran Guerra, el mapa político de Europa sufrió cambios de significación, particularmente en Europa Central, circunstancia que determinó la modificación del régimen de algunos ríos ya internacionalizados. En el artículo 23 inciso e) del Pacto de la Sociedad de las Naciones, los Estados miembros se comprometían a tomar todas las disposiciones necesarias para asegurar y mantener la libertad de comunicación y de tránsito, así como de otorgar un trato equitativo para el comercio de todos los miembros de la Organización.

En el Tratado de Versalles, se estableció que el Elba, el Oder, el Niemen y el Danubio desde Ulm y sus canales laterales que sirvieren de acceso al mar a más de un Estado, eran internacionales y que en dichas vías acuáticas, los nacionales, los bienes y las banderas de todas las potencias serían tratadas en absoluto pie de igualdad (artículos 331 y 332). Por el mismo tratado se amplió la libertad de navegación por el Rhin. Igualmente se creó la Comisión Internacional del Danubio que tuvo a su cargo asegurar la libertad de navegación por este río y se crearon también otras Comisiones Internacionales de la que formaban parte los Estados no ribereños, a los efectos de controlar el cumplimiento del tratado en los diversos Estados. Las características de los tratados de paz de 1919-1920 y la excesiva tendencia a la internacionalización, sobre bases dudosas en cuanto a la libertad con que los Estados manifestaron su consentimiento, trajeron como consecuencia resistencias políticas de los Estados ribereños. La administración

\footnotetext{
${ }^{11}$ OPPENHEIM, M. A. Op. cit., pág. 20.

12 REUTER, P. Derecho Internacional Público, (Trad. de Truyol y Serra), Barcelona, 1962 , pág. 218 .
} 
instrumentada a través de comisiones internacionales sólo podía ofrecer garantías si se ponía en pie de igualdad a todos los ribereños ${ }^{13}$. No fueron pocos los que juzgaron que la internacionalización fue la expresión de la dominación de las potencias comerciales, marítimas y coloniales, determinando un desarrollo artificial del derecho internacional fluvial que fue sustituido por la regionalización de la administración internacional de los ríos, con representación exclusiva de los Estados ribereños, que fue la tendencia dominante a partir del fracaso de los regímenes instaurados en $1919^{14}$.

\section{La Convención de Barcelona de 1921}

La Sociedad de las Naciones, en cumplimiento de lo dispuesto en el Tratado de Versalles, convocó en 1920 a una Conferencia que se reuniría al año siguiente. Tuvo un carácter amplio, suscribiéndose un Convenio y un Estatuto sobre la libertad de tránsito, un Convenio y un Estatuto sobre el régimen de las vías navegables de interés internacional, y un Protocolo adicional a este último convenio.

La adopción de estos instrumentos hizo pensar que se daba un paso significativo en la evolución del Derecho internacional fluvial, pero, en los hechos, el régimen allí establecido no alcanzó la universalidad que sus artífices anhelaron. De allí que su valor fuera más doctrinario que positivo.

Existía la convicción de que la reiteración del principio de libertad de navegación en un estatuto elaborado por un número bastante apreciable de Estados que pertenecían a diversas partes del globo, constituía una “...nueva e importante etapa hacia el establecimiento de la cooperación entre los Estados sin perjudicar en forma alguna sus derechos de soberanía o de autoridad" 15 .

Al margen de sus aciertos y falencias, el Estatuto sobre el régimen de las vías navegables de importancia internacional, como ya se destacó, enunció un nuevo concepto de río internacional, que se apartaba de la idea desarrollada en Viena. En efecto, según la definición de Viena, la determinación de la calidad internacional de un río estaba dada por un elemento natural, cual era su navegabilidad, y por un elemento jurídicopolítico, cual era el hecho de que el río separara o atravesara más de un Estado. Se ha observado, que este último elemento tiene un carácter accidental y variable, que no guarda relación con la verdadera utilidad del río. Existen ríos de estas características que no tienen ninguna relevancia como medio de comunicación, mientras que hay otros que siendo enteramente nacionales, constituyen vías naturales de inapreciable valor

13 DE VISSCHER P. Ob. Teoría y Realidades en Derecho Internacional Público (Trad. de Sancho Riera), Barcelona, 1964. En "Cours Général de Principes de Droit International Public", RCADI, Vol. 86, 1954-II pág. 230.

${ }^{14}$ RAUX, J. Régionalisation et centralisation en matière d'administration fluviale, en RGDIP, T. 73, 1969, pág. 637-743.

${ }^{15}$ v. Preámbulo de la Convención sobre Régimen de las Vías Navegables de Importancia Internacional. 
económico internacional. Pero esta última circunstancia no debe ser exagerada, al punto de pretender establecer derechos a favor de terceros Estados afectando la libre voluntad del país cuyo territorio fue agraciado por la naturaleza y de cuyo cauce tiene su entero uso y disfrute.

En realidad, la definición de Barcelona, no se apartaba del criterio tradicional en cuanto caracterizaba al río internacional como vía de agua naturalmente navegable que divide o atraviesa diversos Estados, pero -y allí debe encontrase la innovación -, introducía la idea de principal función económica, la cual está determinada por el carácter navegable de la vía acuática, primordialmente.

El régimen de Barcelona mostraba un carácter amplio en cuanto a la esfera de aplicación, por cuanto se extendía o toda vía acuática, siempre que fuera naturalmente apta para la navegación comercial que se practica de ordinario, sean estas aguas corrientes o no, abarcando en consecuencia los lagos.

La noción de vía acuática de interés internacional, constituye una expresión amplia y comprensiva también de las vías fluviales nacionales, aunque para la incorporación de estas últimas al Régimen de Barcelona, era necesario el consentimiento expreso de los Estados.

El sistema instaurado en la Convención de Barcelona, tenía un carácter cerrado. En relación a las obligaciones de los Estados ribereños, éstos debían abstenerse de adoptar medida alguna susceptible de restringir la navegabilidad o de disminuir las facilidades de la navegación y estaban obligados a tomar todas las medidas útiles para suprimir los obstáculos y los peligros que pudieran presentarse. Igualmente estaban obligados los ribereños a realizar obras y trabajos de entretenimiento, en cuyos gastos debían participar todos los Estados ribereños (artículo 10). El Estatuto no era aplicable a la navegación de barcos de guerra o barcos que desempeñaran funciones de policía o que ejercieren en cualquier forma una función pública. Quedó en duda, sin embargo, si el régimen subsistía en época de guerra.

En lo que atañe a la administración de las vías de agua de interés internacional, el Régimen de Barcelona no se inclinó por el establecimiento de comisiones internacionales, sino que tan sólo previó la posibilidad de su creación.

La falta de ajuste a la realidad internacional de los principios de Barcelona y el exceso de internacionalización, determinaron que tuvieran una escasa aplicación práctica. La mayoría de los Estados que la ratificaron no eran ribereños de los ríos a los cuales estaban destinados esencialmente sus normas. La situación de Europa después de la Conferencia de 1921, tanto en el plano político como económico, poco favoreció al desarrollo del derecho internacional fluvial. La denuncia por parte de Alemania de los compromisos contraídos al finalizar la Primera Guerra y la disolución de los organismos danubianos a instancia de Rumania y luego de la misma Alemania y la URSS, constituyeron hechos que en nada contribuyeron a la consolidación de las normas aplicables a la navegación fluvial. 


\section{Regímenes particulares. La navegación fluvial en América}

La navegación de las grandes y vitales vías fluviales de comunicación enclavadas en el continente europeo ocuparía, por su importancia, el temario de los más importantes congresos del siglo XIX y aún del siglo XX, aunque hayan sido los usos diversos a los de la navegación los que en las últimas décadas impulsarían a los ribereños a establecer, por vía convencional, el régimen de su aprovechamiento. Así lo demuestra la evolución del régimen jurídico de los ríos Rhin, Escalda, Danubio, Mosa, entre otros. No es diferente la situación de las cuencas y ríos del Continente africano, como el Nilo, el Congo, el Níger, el Tchad, el Senegal, etc. En Asia, el Indo, el Ganges, el Mahakali, inter alia.

Por su peculiaridad, hemos centrado nuestra atención en la evolución de la cuestión en América.

La evolución de los principios aplicables a los ríos internacionales en América, estuvo signada por concepciones diferentes, predominando la tendencia a la concesión de la libertad de navegación por parte de los Estados ribereños, mediante la concertación de tratados específicos.

Tal realidad también habría de conspirar contra la formulación de normas consuetudinarias de validez universal. Mientras que en Europa, el reconocimiento uniforme de determinados principios o la conducta constante de muchos Estados, manifestada en la incorporación de ciertas cláusulas en las convenciones celebradas en el ámbito continental, indujo a algunos tratadistas a afirmar la existencia de un verdadero derecho consuetudinario, tal reconocimiento difícilmente puede ser admitido con carácter general.

En América del Sur, las restricciones a los derechos soberanos de los Estados ribereños en lo que atañe a la navegación, han sido establecidas por vía convencional, no pudiendo los Estados no ribereños invocar derechos basados en la costumbre. Son muy escasas las normas consuetudinarias admitidas como tales, afirmándose que la única regla de este origen, en virtud de una repetición constante y uniforme, es la cláusula incorporada en un número apreciable de tratados y por la cual el Estado ribereño que otorga la libertad de navegación, se reserva para sí la navegación de cabotaje en el río ${ }^{16}$.

En América, sea por actos unilaterales o convencionales, se ha aceptado la libertad de navegación por los ríos internacionales, salvo contadas excepciones. En el Congreso de Lima de 1847, la aplicación de este principio fue reclamado en beneficio de los Estados ribereños. Posteriormente, en la Primera Conferencia Panamericana, celebrada en Washington en 1889, se declaró que tanto los ríos limítrofes como los sucesivos debían estar abiertos a la libre navegación de los Estados ribereños, sin que ello afectara su soberanía. En la Segunda y Quinta Conferencia Panamericana, reunidas en México y Santiago de Chile en 1901

16 BARBERIS, JULIO. Principios jurídicos que regulan la libre navegación en la Cuenca del Plata, en Ríos y Canales navegables internacionales, UNITAR, Buenos Aires, 1971, pág. 202. 
y 1923, respectivamente, se proyectó la convocatoria de una Conferencia Geográfica Fluvial y la Constitución de una comisión de geógrafos encargada del estudio de las comunicaciones fluviales entre las principales cuencas sudamericanas ${ }^{17}$.

La Sexta Conferencia Internacional Americana, celebrada en La Habana en 1926, recomendó a los gobiernos de las repúblicas americanas que tuvieran ríos navegables, que procedieran a realizar estudios técnicos sobre las condiciones de navegabilidad y los obstáculos que la impidieran, como así también de los métodos y costos para la eliminación de esos obstáculos y la posibilidad de establecer conexiones entre los ríos navegables de América, debiendo remitirse todos los antecedentes a la Unión Panamericana ${ }^{18}$. En la Séptima Conferencia Panamericana, realizada en Montevideo en 1933, se aprobó la Resolución LXXXIII, referida a la navegación fluvial, por la que se recomendaba la creación de un Comité Permanente Interamericano de Navegación fluvial que tendría su sede en Río de Janeiro. Este Comité prepararía un congreso geográfico que tendría por fin custodiar los informes técnicos que presentaran los países interesados, sobre la extensión, navegabilidad y eliminación de los obstáculos a la navegación de los ríos que atravesaban sus territorios. Otro de los objetivos importantes era organizar comisiones técnicas de exploración para la formulación de un plan definitivo de conexión de los grandes sistemas hidrográficos sudamericanos ${ }^{19}$.

Las trabas o gravámenes a las comunicaciones fluviales constituyeron una de las preocupaciones llevadas la Conferencia Interamericana de Consolidación de la Paz, celebrada en Buenos Aires en 1936. La Resolución XLIII recomendó a los gobiernos americanos la negociación de tratados bilaterales o multilaterales por los que se comprometieran a no crear trabas o gravámenes nacionales, provinciales o municipales, legales o administrativos, con propósitos impositivos proteccionistas, sobre las comunicaciones fluviales, instándose a la atenuación de los existentes, a condición de reciprocidad ${ }^{20}$.La Reunión de Ministros de Hacienda o Economía en la IV Sesión Extraordinaria del Consejo Interamericano Económico y Social, celebrada en Petrópolis en 1954, abordó la cuestión del mejoramiento del transporte fluvial en América. En la Resolución 26, se disponía, entre otras cosas, la preparación de un programa de largo alcance, que incluyera estudios formulados por técnicos competentes en transportes y que hubieran de servir de base para la elaboración de recomendaciones relacionadas con el desarrollo de la navegación fluvial y lacustre en América ${ }^{21}$.

17 Cf. Conferencias Internacionales Americanas, Dotación Carneghie, Washington, 1938, p. 45.

${ }^{18}$ Ibídem, pág. 414.

${ }^{19}$ Ibídem, pág. 553.

${ }^{20}$ Ibídem, pág 658.

${ }^{21}$ Doc. OEA/Serv.I. VI, 1, CIJ-97, pág. 6. 
Con el tiempo se fue tomando conciencia de que los sistemas fluviales constituían factores de gran importancia para el desarrollo y la expansión económica de los países americanos, debiendo coordinarse los esfuerzos para mantener y mejorar los sistemas fluviales obteniendo el mayor beneficio posible de ellos. Por otra parte, un desarrollo integral, requería considerar la situación de aquellos Estados americanos que por su situación mediterránea, se encontraban en desventaja con respecto a aquellos cuyos territorios están atravesados por vastas redes fluviales que desembocan en los mares.

La determinación del régimen de los ríos internacionales constituyó una preocupación constante en el continente. La problemática se incluyó en la Conferencia Económica de la Organización de los Estados Americanos, realizada en Buenos Aires en 1957. La Resolución XXIII recomendaba a los Estados miembros integrantes de los diversos sistemas fluviales, la celebración de acuerdos para concretar estudios de los ríos internacionales dentro de sus respectivas jurisdicciones a los efectos de facilitar el tráfico internacional e impulsar el desarrollo económico. Con respecto a los Estados mediterráneos, se aconsejaba la adopción de medidas que aseguraran la más amplia libertad de tránsito fluvial, sin impuestos ni limitaciones, para las mercaderías que importaran o exportaran dichos países ${ }^{22}$.

En la Segunda Conferencia Interamericana Extraordinaria, celebrada en Río de Janeiro en 1965, se recomendó a las instituciones financieras internacionales dar preferente atención a los pedidos de asistencia técnica y crediticia para la realización de estudios y ejecución de obras destinadas al mejoramiento de la navegabilidad de los ríos y lagos internacionales americanos ${ }^{23}$.

Contemporáneamente con la labor desarrollada por los Estados americanos en las conferencias y reuniones internacionales precedentemente citadas, en marzo de 1963 se suscribió en Mar del Plata un Convenio Interamericano para facilitar el Transporte Acuático Internacional, tendiente a hacer más accesible los servicios de transporte acuático internacional en el hemisferio occidental, mediante la reducción a un mínimo de las formalidades, requisitos y trámites de documentos para la recepción y despacho de naves y para el tratamiento de pasajeros, tripulación carga y equipaje ${ }^{24}$. Igualmente, para concretar el proceso de integración económica, los Estados Miembros de la Asociación Latinoamericana de Libre Comercio suscribieron en septiembre de 1966 un Convenio sobre transporte por agua, medio éste que puede ser considerado como el más importante para el intercambio de mercaderías entre los países de la Asociación, y de éstos con los países extrazonales. El Convenio previó la creación de una comisión permanente integrada por representantes de cada una de las partes, cuya

\footnotetext{
${ }^{22}$ Ibidem, pág. 8.

${ }^{23}$ Ibidem, pág. 12.

${ }^{24}$ Ibidem, pág. 33.
} 
misión principal consistió hacer realidad los propósitos consignados en el tratado, y vigilar su cumplimiento ${ }^{25}$.

La preocupación por asegurar la libertad de navegación y de mantener las redes fluviales americanas en condiciones adecuadas, se ha manifestado en forma constante en el accionar político de los Estados del continente. Por otra parte, no se puede poner en tela de juicio que los ríos internacionales constituyen un factor de primer orden para la concreción de los procesos de integración iniciados en América Latina.

En América del Norte, existen varios ríos internacionales en los cuales el uso de las aguas para la navegación o para otros fines, ha dado origen a ciertos diferendos que generalmente se han resuelto por la vía del acuerdo entre los ribereños. Tal es el caso, por ejemplo, de los ríos San Lorenzo, Mississippi, Colorado, Tijuana y Grande.

En América del Sur, igualmente existen varias vías fluviales muy importantes cuyo régimen, en los siglos XIX $y \mathrm{XX}$, han provocado desavenencias entre los ribereños y que afortunadamente han sido casi todos solucionados. Es el caso de los ríos Amazonas, Orinoco, Mauri, Paraná, Uruguay, Paraguay y el Río de la Plata, entre otros.

\section{USOS PARA FINES DISTINTOS DE LA NAVEGACIÓN}

En los capítulos anteriores se ha abordado la problemática relacionada con la navegación. Sin embargo, a pesar de que durante muchas décadas la disputa doctrinaria giró en torno al derecho de los ribereños de prohibir a los terceros Estados la libertad de navegación o sobre el alcance de tal derecho, en los años posteriores los adelantos tecnológicos y científicos han permitido a los pueblos la posibilidad de obtener incalculables beneficios mediante la utilización de las aguas fluviales -inter alia-, para fines domésticos, riego, energía eléctrica, agrícolas e industriales.

A continuación estudiaremos los problemas y el régimen jurídico aplicable a esos usos.

\section{Problemas y régimen jurídico}

Si la dificultad de establecer normas generales de validez universal podría ser una de las conclusiones a extraerse del estudio realizado sobre la legislación adoptada en los distintos continentes para determinadas vías acuáticas y la doctrina predominante en los distintos continentes en relación al uso navegación, es previsible suponer que la contraposición de intereses nacionales, que entran a jugar cuando se trata de la explotación de las grandes redes fluviales para otros fines, también haya constituido un obstáculo de primera magnitud para la elaboración de un ordenamiento jurídico internacional de aceptación generalizada.

Un río internacional, se ha sostenido, constituye un sistema extremadamente complejo, donde los Estados ribereños y a veces, los no

\footnotetext{
${ }^{25}$ Ibidem, pág. 38.
} 
ribereños, están vinculados por intereses políticos, estratégicos, económicos o de otra índole, que en no pocos casos están en conflicto. El papel del derecho, consiste en establecer normas que regulen los conflictos de intereses, instaurando un equilibrio equitativo ${ }^{26}$.

Como en otras áreas del Derecho de Gentes, se presenta la dificultad, señala Sauser Hall, de formular, a priori, principios reguladores del aprovechamiento industrial de los ríos y cursos de agua internacionales, siendo poco recomendable la adopción de normas abstractas que dejen de lado la situación política, económica y topográfica de la vía fluvial ${ }^{27}(86)$.

En la realidad, la problemática siempre ofreció muchos interrogantes. La dificultad para establecer principios o normas aplicables al uso y aprovechamiento de ciertas redes fluviales que participan del doble carácter de nacionales e internacionales, son múltiples. Pueden añadirse otras dificultades, como el hecho de que las aguas de los ríos internacionales pueden ser utilizadas en función de consumo o de insumo, o de ambas simultáneamente, produciendo diversas consecuencias jurídicas, como igualmente el impacto ecológico derivado de la modificación de los cursos de agua.

En cuanto a los usos, es necesario destacar que en general, la preferencia de los usos ha sido establecido y resuelto en los acuerdos particulares, sin que pueda sostenerse la existencia de una norma consuetudinaria que consagre un orden determinado o de preferencia ${ }^{28}$. A título ejemplificativo, en el Tratado celebrado entre los Estados Unidos de Norteamérica y la Gran Bretaña sobre los límites fluviales con Canadá, se estableció un orden prioritario obligatorio para las Partes: primero, para fines domésticos y sanitarios; segundo, para la navegación, incluyendo los canales; finalmente, para la producción de energía eléctrica e irrigación. Conservando la primacía del uso doméstico, el Acuerdo entre México y los Estados Unidos de Norteamérica de 1944 sobre la materia, estableció otro orden de precedencia ${ }^{29}(90)$. En el Convenio suscrito entre Argentina y Uruguay creando una Comisión Técnica Mixta para el aprovechamiento de los rápidos de Salto Grande de 1946, se pactó el siguiente orden de prioridad no alterable por ninguna utilización: $1^{\circ}$, fines domésticos y sanitarios; $2^{\circ}$, navegación; $3^{\circ}$, producción de energía; $4^{\circ}$, riego ${ }^{30}$. Algunos acuerdos además

${ }^{26}$ BRIERLY, J.L. Régles Génèrales du Droit de la Paix, en RCADI.,Vol. 58,1936-IV. La diversidad de situaciones que engendran los ríos internacionales que hace impracticable una uniformización a ultranza ha sido señala también por De Visscher, C. (Cf. Cours Général de Principes de Droit International Public, en RCADI,Vol. 86, 1954-II, pág. 491-492).

${ }^{27}$ Op. cit., pág. 471.

${ }^{28}$ MARTÍNEZ-AGULLÓ Y SANCHIS, LUIS. Los tratados y la costumbre en el derecho fluvial internacional, en Revista Española de Derecho Internacional, Vol. XV, $\mathrm{N}^{\circ} 1-2$, 1962, pág. 47.

${ }^{29} \mathrm{Cf}$. textos en Doc. OEA/Ser.I/VI,CIJ-75, Rev., pp. 250 y 407.

${ }^{30} \mathrm{Cf}$. texto en OEA Cuenca del Plata-Aspectos Jurídicos e Institucionales de un Desarrollo Multinacional, Buenos Aires (Argentina), 1969, pág. 223-228. 
han definido estos usos. Tal el caso del Tratado sobre la Cuenca del Indo firmado en 1960 entre la India y Pakistán ${ }^{31}$.

Cabe agregar que los usos no presentan las mismas características. Así, el uso energético y el uso navegación, sin mayores problemas, pueden ser atribuidos en común a los ribereños sin otro límite que el respeto de sus respectivas jurisdicciones. Tratándose del aprovechamiento de las aguas para la irrigación, bebida o uso sanitario, la adjudicación ofrece mayores dificultades. La división por mitades siguiendo una fórmula matemática, sólo sería factible si se tratara de un río internacional limítrofe a lo largo de todo su curso y sin que hubiera aporte de afluentes en su recorrido, hipótesis que difícilmente pueda darse ${ }^{32}$.

Por otra parte, ciertos usos traen como consecuencia la alteración de las propiedades naturales de los cursos de agua, con el consiguiente perjuicio, en el caso de los ríos internacionales, en el territorio de los otros coribereños. Las obras conducentes a regular el régimen del río por alguno de los ribereños puede alterar el régimen hidrográfico en perjuicio de los demás Estados interesados. Igualmente, el volumen de las aguas puede experimentar alteraciones por el consumo o por la construcción de canales que aumenten el caudal con el peligro de inundaciones o, a la inversa, que disminuya el flujo de agua. Mayor gravedad ocasiona la contaminación de las aguas, que puede convertirlas en ineptas para determinados usos.

Tales inconvenientes o potenciales perjuicios que pueden derivarse de un uso abusivo e incontrolado de los cursos de agua internacionales, ha generado una tendencia favorable al establecimiento de una regulación jurídica de alcance general, que contemple equitativamente los intereses de los Estados ribereños.

\section{La problemática en las organizaciones internacionales y otros foros}

En el ámbito de las relaciones interestatales, en noviembre de 1923, bajo el auspicio de la Sociedad de las Naciones, se reunió la Segunda Conferencia General de Comunicaciones y Tránsito. En tal oportunidad se adoptó la Convención Relativa al Aprovechamiento de las Fuerzas Hidráulicas que interesan a varios Estados. Este instrumento, inter alia, reafirma la libertad de todo Estado de ejecutar en su territorio los trabajos para el aprovechamiento de la fuerza hidráulica que desee; establece una acción común en cuanto a los estudios que deben realizarse para encontrar soluciones más favorables a sus intereses; se institucionaliza la negociación, para el caso de que un Estado contratante desee ejecutar trabajos de aprovechamiento de fuerza hidráulica de los que pudieran resultar un perjuicio grave para cualquier otro Estado contratante, negociación que tendrá como objetivo la conclusión de acuerdos destinados a permitir la

\footnotetext{
${ }^{31}$ Ibídem, pág. 181-193.

32 CHIESA, N.E. Regulación Jurídica del Aprovechamiento Hidroeléctrico de Ríos Internacionales, Documento de Trabajo presentado en el Primer Congreso Ordinario de la Asociación Argentina de Derecho Internacional, Mendoza (Argentina), marzo de 1971.p. 27.
} 
ejecución de esos trabajos. Este procedimiento se aplica igualmente cuando un Estado desee ejecutar obras de transporte de fuerza hidráulica, parte sobre su propio territorio y parte sobre el territorio de cualquier otro Estado, o cuando dichos trabajos importen una modificación en el territorio de cualquier otro Estado contratante. Asimismo, se establece la prioridad del uso navegación cuando se tratara de vías navegables de interés internacional y se instituyen mecanismos para la solución de controversias originadas por la aplicación o interpretación de la Convención.

Pese al esfuerzo emprendido, este instrumento sólo fue ratificado por nueve Estados de varios continentes, la mayoría de ellos no poseedores de cursos de agua de interés internacional. En los hechos no tuvo la trascendencia deseada, aunque para algunos puede ser considerado como una manifestación de reglas generales, aplicables a la reglamentación internacional de la utilización de los ríos internacionales con fines industriales, habiendo sido recogidos sus preceptos en un número considerable de convenios internacionales ${ }^{33}$.

Ya creada las Naciones Unidas, la problemática en consideración acaparó la atención de la Asamblea General, órgano que por Resolución 1401 (XIV) de noviembre de 1959, dispuso la realización de estudios preliminares con el ulterior objetivo de emprender la codificación. Se encomendó al Secretario General la elaboración de un informe que reuniera la información suministrada por los Estados acerca de sus leyes y legislación vigente en la materia; un resumen de los tratados bilaterales y multilaterales existentes; un resumen de las decisiones de tribunales internacionales, con inclusión de las sentencias arbitrales y una relación de los estudios ya emprendidos o que estuvieren realizando las organizaciones internacionales no gubernamentales competentes en cuestiones de Derecho Internacional ${ }^{34}$. Tiempo después, la Secretaría General publicó un documento que contenía un repertorio de los tratados sobre la materia y una síntesis de la jurisprudencia respectiva ${ }^{35}$.

El Consejo Económico y Social y otros organismos especializados de las Naciones Unidas también realizaron estudios y emprendieron actividades de carácter técnico relativas al aprovechamiento de recursos hidráulicos. El Consejo, en varias resoluciones ${ }^{36}$ ha señalado la importancia de la cooperación en el campo del control y utilización de los recursos de las cuencas hidrográficas para el desarrollo económico, así como la contribución de podían prestar las organizaciones internacionales. Por Resolución 675 del $25^{\circ}$ período de sesiones, recomendó la creación de un centro que

\footnotetext{
${ }^{33}$ RUIZ MORENO, I. El aprovechamiento de los ríos internacionales en América, en Estudios de Derecho Internacional Público, Buenos Aires, 1965, pág. 106-107.

34 UN/AG, Documentos Oficiales, XIV Período de sesiones, Suplemento $\mathrm{N}^{\circ} 16$ $(\mathrm{A} / 4354)$.

35 v. Publicaciones de Naciones Unidas, 58/II/B/3 y Nations Unies, Serie Legislative, ST/LEG/SER/B/12, respectivamente.

${ }^{36}$ v. Resolución 436 del XII Período de Sesiones (1951) y Resolución 417 del XIV Período de Sesiones (1952).
} 
coordinaría las tareas de diversas entidades de las Naciones Unidas en el área del aprovechamiento de los cursos de agua internacionales. El Water Resources Development Center, promovió estudios sobre las cuencas hidrográficas de varios Estados e investigaciones sobre el desarrollo de aguas subterráneas, abastecimiento de agua a las comunidades y contaminación de aguas. A partir de 1964 se reestructuró la función de este órgano, otorgándole la atribución de difundir la información pertinente entre los gobiernos y las organizaciones interesadas y fomentar los esfuerzos en orden a la formulación de principios de derecho internacional aplicables a la utilización de los recursos hidráulicos ${ }^{37}$.

Otro hito fue la Conferencia de las Naciones Unidas sobre el Agua, celebrada en Mar del Plata, Argentina, en 1977, convocada por el Consejo Económico y Social en $1973^{38}$. En esta oportunidad de aprobaron 103 recomendaciones generales, 19 recomendaciones regionales concretas y 12 resoluciones, que constituirían el llamado Plan de Acción de Mar del Plata. Muchas de estas recomendaciones y resoluciones estaban vinculadas con el desarrollo de los "recursos hídricos compartidos" y con las "cuencas fluviales".

En cuanto a los emprendimientos regionales, la Comisión Económica para Europa desarrolló una intensa actividad. A través de su Comisión de Energía Eléctrica, publicó en 1952 un informe sobre algunos aspectos jurídicos del desarrollo hidroeléctrico. Este estudio contiene conclusiones que reflejaban la realidad en esa época ${ }^{39}$. Se señala que los Estados ejercen el derecho de soberanía y propiedad de las vías fluviales que corren por su territorio, sean fronterizas o sucesivas, pero se advierte que las construcciones hidroeléctricas realizadas por un Estado ribereño pueden afectar negativamente a los otros Estados ribereños del curso de agua. Asimismo se señala que físicamente las vías acuáticas constituyen unidades indivisibles que tiene una misión natural que cumplir, cual es la de servir a los intereses de la humanidad; que resultaba difícil establecer prioridades entre estos intereses y complicado realizar una clasificación de los usos pertinentes en razón de la importancia intrínseca de cada uso, sin perjuicio de la importancia del uso de tales vías para la promoción del bienestar común; que la idea de comunidad de intereses y de la equidad deben contribuir a la concertación de los acuerdos que sean necesarios; que en materia de construcciones hidroeléctricas, cada caso presenta sus propias peculiaridades, según la importancia que le atribuya cada Estado y la naturaleza de la corriente de aguas de que se trate, por lo que el valor absoluto del perjuicio sufrido, cambia considerablemente.

De tales conclusiones podían extraerse algunos principios: Primero, que todo Estado "tiene derecho a desarrollar unilateralmente la sección de la vía acuática que atraviesa su territorio o le sirve de frontera, en tanto en

\footnotetext{
${ }^{37}$ Doc. OEA/Ser.I/VI,CIJ-75, Rev., pág. 30-32.

${ }^{38}$ Resolución 1761C (LIV) de 18 de mayo de 1973.

${ }^{39}$ Ibídem, pág. 35-37;
} 
cuanto tal desarrollo cause en el territorio de otro Estado solamente perjuicios ligeros o inconvenientes menores compatibles con las relaciones de buena vecindad". Segundo, que cuando el perjuicio que se causare fuere grave y permanente, los trabajos de desarrollo podrán realizarse mediante un acuerdo previo. Tercero, que ningún Estado tiene el derecho de oponerse al desarrollo hidroeléctrico de una sección de la vía acuática internacional situada en el territorio de otro Estado, si dicho desarrollo le ocasiona tan sólo un perjuicio ligero. Cuarto, que la determinación de la naturaleza del perjuicio o gravedad del mismo, depende del caso concreto, debiendo regirse por las buenas relaciones de vecindad. Se afirma que estos principios habían sido generalmente aceptados, hecho que permite sostener que constituían la base del régimen regulador del aprovechamiento hidroeléctrico de los ríos y lagos internacionales.

Esta misma Comisión también abordó la cuestión de la contaminación de las aguas, declarando que tal problema constituía una responsabilidad fundamental de todo gobierno, exigiendo la colaboración internacional y la cooperación de las comunidades locales y de todos cuantos usaran esas aguas, formando parte integral de la política de recurso y utilización de las aguas, el control de la contaminación ${ }^{40}$. No estuvo ausente el problema relativo a las dificultades jurídicas y administrativas que tendían a impedir suministros de energía eléctrica a través de las fronteras, y las dificultades jurídicas y administrativas que impedían el desarrollo hidroeléctrico de las vías fluviales contiguas o sucesivas.

La cuestión continuó en la agenda de la Comisión y se aprobaron en los años siguientes varios instrumentos y declaraciones relacionados con la prevención de la contaminación de las aguas transfronterizas y con la utilización racional de tales aguas, entre otros. Igualmente se adoptó en 1989 una Carta para la gestión de las aguas subterráneas, y en 1990 un Código de conducta sobre contaminación accidental de aguas interiores transfronterizas.

Quizá la obra más relevante ha sido la elaboración de los proyectos que culminaron con la adopción en 1992, en Helsinki, de una convención regional, que abordaremos más adelante.

En el ámbito europeo, cabe recordar la Carta Europea sobre el Agua adoptada en 1967 en el ámbito del Consejo de Europa, que tuvo una gran repercusión en su momento.

La Comisión Económica para el África, realizó una encomiable labor para facilitar a los países del continente la planificación de sus políticas relativas al desarrollo de los recursos hidráulicos, a la promoción del desarrollo de las cuencas de los ríos internacionales africanos, a los estudios sobre necesidades y recursos de agua de los diversos países, a la coordinación de las investigaciones, etc. Uno de sus informes sirvió de base en 1964, para la negociación y firma de un acuerdo sobre Navegación y Cooperación entre los Estados ribereños del río Níger, sus tributarios y

${ }^{40}$ Ibídem, pág. 38-40 
subtributarios. También realizó estudios relativos a la promoción del desarrollo de la cuenca del río Senegal, que luego condujo a la firma de una convención, en 1964. Igualmente la cuenca del lago Tchad, fue motivo de estudios especializados ${ }^{41}$.

La Comisión Económica para Asia y el Lejano Oriente, emprendió una importante tarea a través del Comité de Coordinación de investigaciones en la cuenca del río Bajo Mekong, cuyos intereses afectaban a cuatro Estados ribereños. El Comité adoptó inicialmente un programa básico de estudios e investigaciones para el desarrollo de los recursos hidráulicos del citado río, y para la navegación, irrigación y producción de energía eléctrica.

En 1964, se celebró en Bangkok la Sexta Conferencia Regional sobre Desarrollo de los Recursos Hidráulicos, que efectuó un examen de los progresos alcanzados en el desarrollo de dichos recursos, y estudió criterios para la formulación de políticas nacionales sobre aguas, observando que en la región, la primera prioridad para el uso de las aguas era el fin doméstico, siguiéndole los usos para fines agrícolas e industriales ${ }^{42}$. El Comité del Mekong, ha publicado varios informes y elaborado ambiciosos programas de desarrollo, hecho que ha determinado -v.g.-, que en los proyectos de aprovechamiento de la cuenca del Bajo Mekong participaran, además de los países ribereños, otros Estados continentales y extra continentales, y órganos y entidades de las Naciones Unidas. Sólo hemos mencionado algunos logros iniciales de aquellas Comisiones del Consejo Económico y Social, que siguieron tratando la temática en fechas posteriores.

\section{La cuestión en el continente americano}

En relación al continente americano, la Comisión Económica para América Latina ha desarrollado una intensa tarea de investigación y estudio de los recursos hidráulicos de la zona. Ha publicado varios informes y prestado especial atención a la inmensa cuenca de drenaje que constituye el sistema del Río de la Plata, así como otras cuencas fluviales de interés regional en Panamá y Centroamérica ${ }^{43}$.

Debe destacarse que el uso y aprovechamiento de los ríos internacionales y su regulación jurídica, ha sido motivo de especial consideración en el continente americano, habiéndose enunciado normas específicas que han pretendido asegurar una justa distribución del caudal en beneficio de los Estados corribereños.

La Sexta Conferencia Panamericana celebrada en La Habana en 1928, aprobó una Resolución en la que se encomendaba a la Unión Panamericana que efectuara estudios a través de órganos competentes -Junta Internacional de Jurisconsultos-, de la cuestión relacionada con la reglamentación del uso industrial y agrícola de los ríos internacionales ${ }^{44}$. La Comisión Permanente

\footnotetext{
${ }^{41}$ Doc. OEA Ser.I/VI, CIJ-75, Rev., pág. 45-47.

42 Ibídem, pág. 48-56.

${ }^{43}$ Ibídem, pág. 35-37.

${ }^{44}$ Conferencias Internacionales Americanas, Dotación Carnegie, Washington, 1938, pág. 405 .
} 
de Codificación del Derecho Internacional Público, en cumplimiento de esta Resolución, elaboró un informe sobre los principios generales que pudieran facilitar acuerdos regionales entre los Estados ribereños, sobre el uso industrial y agrícola de los ríos internacionales, informe que trataría la Séptima Conferencia, que se reuniría en Montevideo, en 1933.

En esta oportunidad, se aprobó la Resolución LXXII referida al uso industrial y agrícola de los ríos internacionales, que enunció principios y mecanismos procesales de gran importancia, tales como: a) que cuando sea necesario realizar un estudio de las aguas, el Estado que no quisiere efectuarlos, debe facilitar por todos los medios al otro Estado interesado y por cuenta de éste, la realización de dichos estudios en su territorio; b) que los Estados tienen el derecho exclusivo de aprovechar las aguas de los ríos internacionales para fines industriales y agrícolas en el margen que se encuentra bajo su jurisdicción, no pudiendo perjudicar el igual derecho que corresponde al Estado vecino, en la parte sometida a su jurisdicción. Este principio, aplicable a los ríos contiguos o fronterizos también se extiende a los sucesivos; c) que ningún Estado puede realizar alteraciones en los cursos de agua de carácter internacional que puede resultar perjudicial al otro Estado interesado, sin el consentimiento de este último; d) que si se fuera a producir un perjuicio y los daños fueran susceptibles de reparación, las obras sólo podrían realizarse después de que se solucione el incidente sobre indemnización o compensación de daños; e) que tanto en los ríos contiguos como en los sucesivos, las obras de aprovechamiento industrial no deben perjudicar la libre navegación de los mismos; f) que el Estado que proyecta realizar obras en ríos internacionales, debe previamente comunicarlas acompañando la documentación que permita evaluar el alcance de dichas obras; y g) que en caso de falta de acuerdo por la vía diplomática, debe recurrirse a la conciliación o a otro procedimiento establecido en convenciones vigentes en América y, en último caso, al arbitraje ${ }^{45}(135)$.

Ya creada la Organización de Estados Americanos, la problemática atrajo la atención de sus órganos. En marzo de 1963, Brasil propuso la celebración de una conferencia especializada con el fin de examinar en el ámbito continental la cuestión del aprovechamiento de los ríos internacionales y se elaboraran medidas tendentes a su regulación ${ }^{46}$. Aunque la iniciativa contó con el apoyo de algunos gobiernos, otros Estados manifestaron que ella debía tener lugar después de conocidos los resultados de los estudios realizados por el Comité Jurídico Interamericano y el Consejo Interamericano de Jurisconsultos. De conformidad con una resolución aprobada por este último órgano, el Comité Jurídico Interamericano dispuso abordar el tema de los ríos internacionales ${ }^{47}$. En los periodos de sesiones de 1962 y 1963, consideró numerosos antecedentes

\footnotetext{
${ }^{45}$ Ibídem, pág. 543-544.

${ }^{46}$ Doc.OEA/Ser. I/VI, CIJ-75, Rev., p. 5.

47 Informe del Comité Jurídico Interamericano sobre la labor desarrollada durante su período de sesiones de 1959, Doc. CIJ-47, pág. 13-14.
} 
sobre la materia, aprobando en este último año un Estudio y Proyecto de Convención sobre el uso Industrial y Agrícola de Ríos y Lagos Internacionales, documento que fue remitido a la Secretaría General de la organización a los efectos de que ésta lo hiciera llegar a los Estados miembros para que formularan observaciones ${ }^{48}$.

En tal instrumento, el Comité señaló que durante muchos años, el derecho internacional se había ocupado de la navegación y de la pesca en los ríos internacionales, pero que había cobrado importancia la necesidad de dar solución a aquellos problemas que surgían con motivo del aprovechamiento de los ríos en obras de gran utilidad para la producción de energía eléctrica o hidrotérmica, o trabajos de irrigación agrícola, y otros usos susceptibles de disminuir y aún agotar el caudal o modificar la composición química de sus aguas. Destacaba igualmente, que los grandes progresos técnicos habían modificado substancialmente la utilización de la fuerza hidráulica, circunstancia que podría ejercer gran influencia en el curso de los ríos, surgiendo la necesidad de establecer reglas o principios que delimitaran los respectivos derechos de los Estados, conciliando sus intereses ${ }^{49}$. El proyecto del Comité Jurídico Interamericano, como así también las enmiendas y observaciones realizadas por algunos Estados, conjuntamente con una edición revisada del documento sobre antecedentes en materia de ríos internacionales preparado por la División de Codificación del Departamento de Asuntos Jurídicos, fueron tratados en la sesión de 1965 por el Consejo Interamericano de Jurisconsultos. En esta oportunidad, se aprobó una resolución relativa al Proyecto de Convención sobre el Uso Industrial y Agrícola de los Ríos y Lagos Internacionales ${ }^{50}$, en el que se señalaba la importancia de la materia para el desarrollo de los recursos fluviales de los países americanos, y que la normativa destinada a regir las relaciones entre ellos no debía pasar "de la afirmación de los principios básicos y fundamentales de manera que no se excluya, en hipótesis concretas, la consideración de las particularidades de cada río o lago". La resolución fijó también algunas pautas básicas que debían ser consideradas en la preparación del texto revisado del proyecto de convención, tarea esta que se encomendaba al Comité Jurídico Interamericano para ser emprendida en el periodo de sesiones de 1965.

El proyecto debía contener exclusivamente normas para la utilización de las aguas de los ríos y lagos internacionales para fines industriales y agrícolas. Además, debían seguirse algunas pautas como: las normas específicas sobre estas materia sería objeto de convenios bilaterales o regionales entre los Estados ribereños; lo que dispusiera la Convención no afectaría los convenios bilaterales o regionales; la utilización de las aguas para los citados fines no debían afectar la navegación ni causar perjuicios

\footnotetext{
${ }^{48}$ Doc. OEA/Ser.I/VI.2, CIJ-67.

49 CAICEDO CASTILlA, J. La obra del Comité Jurídico Interamericano", Río de Janeiro, 1966, pág. 140-143.

${ }^{50}$ Doc. OEA/Ser. C/IV. 5, CIJ-77, pág. 9-11.
} 
"substanciales" a los Estados ribereños o alterar las fronteras; se debía establecer un procedimiento de información o consulta; debía fijarse un procedimiento especial en caso de falta de acuerdo; debía asegurarse la cooperación para la realización de estudios, etc.

De acuerdo con la resolución del Consejo Interamericano de Jurisconsultos, el Comité Jurídico Interamericano elaboró un proyecto revisado de convención en el que se siguieron las pautas precedentemente mencionadas y se recogieron algunas sugerencias de los Estados. Uno de los aspectos destacables de este proyecto fue haber introducido varias definiciones en relación a qué debía entenderse por ríos y lagos internacionales y sus usos. En el informe que precede al proyecto ${ }^{51}$, se efectúan algunas reflexiones sobre la conveniencia o no de establecer definiciones en un tratado, señalándose que había prevalecido un criterio favorable, en razón de que se trataba de una materia nueva en el derecho internacional convencional, y que en muchas ocasiones había discrepancias entre los gobiernos o entre los tratadistas sobre la noción misma de los asuntos que se pretendía regular en el convenio.

Siguiendo la noción más generalizada, se definieron los ríos internacionales (artículo 3), como "aquellos cuyo curso atraviesa o separa dos o más Estados", denominándose los primeros "sucesivos" y los segundos "contiguos". Por lagos internacionales, debían entenderse "aquellos cuyas márgenes pertenecen a más de un Estado". En cuanto a los usos, se entendía que uso agrícola era "el aprovechamiento del agua para riego u otros usos agropecuarios"52 y por uso industrial "el empleo de las aguas para la producción de energía eléctrica y otros fines industriales". Durante la discusión de este artículo, el Comité consideró la propuesta de Guatemala de introducir una definición de reservas hidrográficas, concebidas como "las aguas que pertenecen a un Estado y que no está en condiciones de utilizar total o parcialmente pero cuyo aprovechamiento futuro es posible para su desarrollo económico"53. Sin embargo, se estimó que tal propuesta excedía los mandatos del Consejo Interamericano de Jurisconsultos. De conformidad con las mismas pautas, se estableció también que el uso industrial y agrícola de los ríos y lagos internacionales que estaban bajo la soberanía de un Estado, no implicaba desconocer el eventual derecho de los demás ribereños (artículo 4); que dicho uso no debía perjudicar la navegación de tales vías acuáticas ni causar perjuicios substanciales, de acuerdo con el derecho internacional a los demás ribereños o alterar sus fronteras (artículo 5); que si como consecuencia de ese aprovechamiento, resultara un daño o perjuicio

51 Doc. OEA/Ser. i/VI. 2, CIJ-79. Uso industrial y agrícola de los ríos y lagos internacionales, pág. 8-9.

${ }^{52}$ En base a una propuesta del El Salvador, que entendía que el uso agrícola no sólo comprendía el riego, sino también otras formas de aprovechamiento, tales como captaciones para abrevar ganado, desarrollo de pequeñas industrias y otros, se modificó el proyecto originario.

${ }^{53}$ Doc. OEA/serví. 2, CIJ-79, pág. 10-11. 
a otro Estado interesado, era necesario el consentimiento de ese Estado, como así también la indemnización del daño o perjuicio, cuando éste fuera reclamado (artículo 6); que ningún Estado podría aprovechar o autorizar el aprovechamiento de un río internacional en condiciones menos estrictas que aquellas que, por ley, costumbre o uso, estuvieren sometidos los aprovechamientos de los ríos internos (artículo 7).

En el proyecto de Convención en examen se reconoció igualmente la necesidad de una notificación previa y por escrito de los proyectos de obras para el aprovechamiento de estas aguas, debiendo el Estado que pretende realizar las obras, acompañar toda la documentación técnica necesaria para que los demás Estados interesados pudieran disponer de elementos de juicio suficientes para determinar el alcance de las obras (artículo 8). La respuesta a esta notificación debía darse en un plazo de seis meses y si vencido este término no se obtuviera respuesta, se consideraría como una aceptación tácita. Si por el contrario, se formularan objeciones de carácter técnico o relativas a daños y perjuicios previsibles, cuya naturaleza y estimación debían consignarse en el mismo documento, se preveía la constitución de la Comisión Mixta que examinaría la materia (artículo 9). Cualquier divergencia o conflicto que se suscitara con motivo del uso y aprovechamiento de las aguas de los ríos y lagos internacionales para fines agrícolas e industriales, debían resolverse, según el proyecto, por los procedimientos pacíficos establecidos en el sistema interamericano.

Puede constatarse que las pautas establecidas por el Consejo Interamericano de Jurisconsultos y receptadas en este proyecto, en general incorporan los principios proclamados en la Séptima Conferencia Interamericana y que en su mayoría eran los reconocidos en materia de utilización y aprovechamiento de las aguas de los ríos y lagos internacionales. Más aún, muchas de las ideas desarrolladas en este proyecto, como se verá, están reflejadas en la Convención de 1997. Sin duda constituyó una de los intentos más destacados en el continente de regulación de los derechos y obligaciones de los Estados comprometidos en el aprovechamiento de los ríos y lagos internacionales. Lamentablemente, sólo quedó como proyecto.

En el temario de la Segunda Conferencia Interamericana Extraordinaria, celebrada en Río de Janeiro, en 1965, se incluyó también la cuestión de la utilización agrícola, industrial y comercial de los ríos y lagos internacionales y su conveniencia de convocar una conferencia especializada. Debatido el tema, se aprobó la Resolución X, en la que se materializó dicho anhelo, convocándose a una Conferencia especializada con el propósito de examinar dicha cuestión y "suscribir el o los instrumentos internacionales que contengan normas generales en la materia" ${ }^{54}$.

En el mes de octubre del mismo año, se celebró en Mar del Plata, Argentina, una Conferencia Especializada para tratar problemas relacionados

\footnotetext{
${ }^{54}$ Actas y documentos de la Séptima Conferencia Interamericana Extraordinaria, Vol. I, pág. 307.
} 
con la conservación de los recursos renovables del Continente, aprobándose los llamados Principios de Mar del Plata. Durante los debates, se estimó que en muchas zonas en donde las disponibilidades hídricas resultaban escasas, se continuaba desarrollando o promoviendo "usos consuntivos del agua de demandas unitarias elevadas en relación al valor económico agregado", razón por la cual el rendimiento económico de usos alternativos aconsejaba modificaciones en las prioridades de utilización. Ello determinó una recomendación a los Estados Miembros de la OEA, para que al encarar proyectos de aprovechamiento múltiple de sus recursos hídricos, realizaran estudios de rendimiento económico del agua por unidad consumida en cada uso alternativo de la misma ${ }^{55}$. Asimismo, la Conferencia advirtió que la deforestación constituía una de las causas principales de la disminución del volumen de las aguas superficiales, y exhortó a los Estados Miembros a tomar medidas proteccionistas para evitar la contaminación de los abastecimientos de agua potable.

En 1966, en su reunión de Buenos Aires, el Consejo Interamericano Económico y Social, en base a un proyecto de resolución sobre regularización y aprovechamiento económico de las cuencas y accidentes hidrográficos en América Latina, presentado por varios Estados americanos, aprobó la Resolución 24-M/66 por la que recomendaba a los países miembros de la Alianza para el Progreso la iniciación de estudios conjuntos para la regularización y aprovechamiento económico de las vías, cuencas y accidentes hidrográficos de la región, con el objeto de promover mediante proyectos multinacionales, su utilización en común, en los transportes, la producción de energía eléctrica, obras de regadío y otros usos ${ }^{56}(146)$.

En la $15^{\circ}$ Conferencia Interamericana, celebrada en Costa Rica, en abril de 1967, se aprobaron tres resoluciones sobre ríos internacionales ${ }^{57}(147)$, sugiriéndose a la OEA la convocatoria a la mayor brevedad posible de una conferencia especializada sobre la utilización de los ríos y lagos internacionales para fines industriales, agrícolas y comerciales. Ella fue convocada por la Segunda Conferencia Interamericana Extraordinaria.

La década del 60 fue muy propicia en el continente americano para el tratamiento de la problemática desde múltiples perspectivas, incluyendo la comercial, coincidiendo con el desarrollo de las ideas integracionistas que intentaron encontrar cause en los diversos tratados suscritos entre los Estados de la región, dando origen a procesos como la Asociación Latinoamericana de Libro Comercio, el Mercado Común Centroamericano, el Pacto Andino, etc.

También la cuestión fue examinada en el ámbito de las organizaciones no gubernamentales e instituciones científicas del continente. La Federación Interamericana de Abogados, en su Décima Conferencia, celebrada en

\footnotetext{
${ }^{55}$ Doc. OEA/Ser. I/VI, CIJ-75, Rev., pág. 12-13.

${ }^{56}$ Ibídem, pág. 14.

${ }^{57}$ Ibídem, pág. 584-586.
} 
Buenos Aires, en 1957, aprobó una resolución sobre ríos internacionales, en la que se enuncian "principios generales que forman parte del derecho internacional actual", aplicable a los ríos y lagos internacionales, que denomina "sistema de aguas internacionales" $58(148)$.

Entre tales principios, se destacan: a) el derecho de los Estados que tengan parte de un sistema de aguas internacionales bajo su jurisdicción, a aprovecharlo, siempre que no afecte el igual derecho de los Estados que tienen otra parte del sistema bajo su jurisdicción; b) el deber de los Estados que tengan parte de un sistema de aguas internacionales bajo su jurisdicción, de reconocer el derecho de los demás Estados que tengan jurisdicción sobre una parte de ese sistema, de compartir los beneficios, tomando como base el mantenimiento del status de utilización del momento y las necesidades de desarrollo futuro; c) el deber de los Estados que tengan parte de un sistema de aguas internacionales bajo su jurisdicción, de no efectuar cambios en su régimen cuando puedan producir efectos adversos en el aprovechamiento de otro u otros Estados que tengan parte en el mismo sistema, salvo que tengan su conformidad; d) que el derecho internacional público reconoce de que si por naturaleza del territorio bajo la jurisdicción de un Estado bajo el cual corren aguas de un sistema internacional se deriva algún beneficio para dicho Estado, tal beneficio se aprovecharía en forma exclusiva. La resolución recomienda el recurso a una Comisión de Arbitraje o a la Corte Internacional de Justicia para dirimir los desacuerdos, y la constitución de una comisión permanente con el objeto de profundizar los principios jurídicos generales en la materia y que dictaminaría -inter alia- sobre el problema de los Estados no ribereños que pudieran tener intereses vinculados a un sistema de aguas internacionales; la cuestión de la indemnización y prevención de actos ilegales en el uso de las aguas internacionales; el problema de la contaminación; la cuestión de la prioridad de los diferentes usos, etc.

\section{La práctica convencional}

Existe hoy una cantidad considerable de tratados o convenios bilaterales y multilaterales celebrados entre los Estados a los efectos de regular el uso y aprovechamiento de los ríos y otras aguas internacionales, desde las más diversas perspectivas. Muchos de ellos, por sus particularidades han sido ya examinados en los apartado anteriores. No obstante, como lo anticipáramos, omitiremos un examen pormenorizado de ellos, aunque puede destacarse que, salvo contadas excepciones, los cursos de agua internacionales, en todos los continentes, han sido objeto de regulaciones convencionales por parte de los coribereños.

Muchos son los repertorios de acuerdos y otros instrumentos referidos a la materia. Con el auspicio de la FAO, se ha efectuado una recopilación de aproximadamente 2000 documentos jurídicos internacionales de la más

\footnotetext{
${ }^{58}$ Ibídem, pág. 581-583.
} 
variada naturaleza, que comprende un período que corre desde el año 805 de nuestra era, hasta 1977. Alrededor de 350 convenios aún se encuentran en vigor. Gran parte de ellos reflejan la práctica convencional tanto en lo que atañe al uso navegación como a los otros usos ${ }^{59}$.

\section{Principios desarrollados}

Los antecedentes considerados en los capítulos anteriores, en particular la vasta elaboración doctrinaria realizada por algunas organizaciones internacionales e instituciones científicas y las cláusulas incorporadas en los numerosos acuerdos suscriptos, nos permiten una aproximación a ciertos principios generales aplicables al uso y aprovechamiento de los ríos y lagos internacionales en la época en que la Comisión de Derecho Internacional comenzó formalmente con su labor codificadora. Sin embargo, habrá que advertir para una correcta valoración, la relativa ausencia de normas consuetudinarias. Al respecto, es posible señalar algunos de ellos.

El derecho de los Estados de aprovechar con carácter exclusivo las aguas de los ríos internacionales que surcan el territorio sometido a su jurisdicción para fines agrícolas, industriales y otros, constituye uno de los principios básicos que informa la temática, siendo reconocido por la doctrina, resoluciones de organismos internacionales, tratados y proyectos de convenciones.

Este derecho de uso y aprovechamiento, considerado como una derivación de la soberanía, debía ser ejercido en forma tal que no causara perjuicios a los iguales derechos de los demás ribereños de la vía fluvial. Debe tratarse de un perjuicio sensible o apreciable, excluyéndose los daños ligeros o inconvenientes menores compatibles con las relaciones de buena vecindad $^{60}$. La naturaleza del perjuicio y el daño y la gravedad del mismo, debe ser determinada en el caso concreto, considerando las circunstancias particulares, por lo que no sería lícito que un Estado se opusiera a la realización de obras en una vía fluvial internacional en la parte que discurre por el territorio de otro Estado, cuando tan sólo le ocasiona un ligero perjuicio.

Todo uso abusivo que produzca un daño, genera la obligación de repararlo o de establecer una compensación, que podrá variar según se trate de un río internacional o de una cuenca. Cada Estado tendría un derecho potencial a la explotación del caudal del agua del río y si éste es navegable, el Estado de aguas abajo tiene el derecho de que se mantenga esta condición de la vía fluvial en la parte que fluye por su territorio.

\footnotetext{
${ }^{59}$ FAO. Estudio Legislativo $N^{\circ}$ 15. Repertorio sistemático por cuenca de convenios, declaraciones, textos legislativos y jurisprudencia relativos a los recursos hídricos internacionales, Roma, 1978. Asimismo un repertorio sobre el tema puede ser consultado en el siguiente enlace: http://www.fao.org/docrep/012/ak470T/ak470T.pdf. 1 de marzo de 2.013.

60 Sería aplicable el viejo adagio de minimis non curat proetor (v. Bar J. Von. L'exploitation industrielle des cours d'eaux internationaux au point de vue du droit international, RGDIP, Vol. 17, 1910 p. 285).
} 
Por otro lado, la cooperación se va constituyendo en uno de los pilares sobre los que debe asentarse la acción de los Estados para el aprovechamiento, conservación, gestión y administración de este vital recurso natural.

Además de estos principios básicos, debe señalarse que la mayoría de los antecedentes examinados permiten inferir la necesidad de que cuando alguno de los coribereños pretenda realizar obras que pudieran alterar las condiciones naturales del río, debe notificar de tales propósitos a los demás ribereños. Entre estos principios procesales ${ }^{61}$, se ha incluido la obligación de los Estados que proyecten realizar una obra sobre un río internacional, de suspender la ejecución del proyecto mientras no se haya arribado a una solución pacífica con los otros u otros coribereños y en tanto y en cuanto haya intención de negociar. Debe recordarse que en el caso del lago Lanoux, el Tribunal arbitral no reconoció un derecho de veto que permitiría a un Estado ribereño inhibir el ejercicio de la competencia territorial de otro coribereño. En caso de desacuerdo, se instituyen mecanismos de solución de controversias, generalmente los que proporciona el derecho internacional clásico, que pueden incluir los medios jurisdiccionales, sea el arbitraje o bien la Corte Internacional de Justicia ${ }^{62}$.

En general, todos estos principios, que tienden a poner de relieve el hecho de que la utilización de los ríos internacionales concierne a todos los Estados interesados en su conjunto y no fragmentariamente a cada uno de los ribereños, han sido incorporados en un número considerable de tratados que regulan el uso y aprovechamiento de los ríos internacionales en los diversos continentes. Fue creando, se ha dicho, a través de un original proceso legislativo internacional, una práctica de la que puede derivarse, además de los ya señalados, principios tales como el reconocimiento del uso anterior; la preservación de uso navegación; la garantía de igualdad para la producción de energía mediante el uso de aguas fronterizas; el aprovechamiento equitativo en consideración de las necesidades para la irrigación y uso doméstico de los Estados interesados, entre otros ${ }^{63}$. Algunos de estos principios, serán examinados desde otra perspectiva, en el capítulo siguiente.

Igualmente, se impone remarcar que el desarrollo del Derecho internacional ambiental en las últimas décadas, habría de tener una influencia importantísima en la materia abordada. Paulatinamente se fueron incorporando nuevos principios y prácticas que se reflejaron en instrumentos regionales y en el Proyecto de la CDI. Hoy los principios de "prevención" y

61 ARMAS BAREA, C. Primeras Jornadas Universitarias sobre Integración Latinoamericana y Desarrollo de la Cuenca del Plata, Córdoba (Argentina), 1968, pág. 179.

${ }^{62}$ Cabe aquí citar como ejemplo el caso que llevara ante la Corte Internacional de Justicia la República Argentina contra la República Oriental del Uruguay. Disponible en: http://www.icjcij.org/docket/files/135/15877.pdf . 21 de febrero de 2.013.

${ }^{63}$ CHIES A, N.E. Op. Cit., pág. 39. 
de "precaución" -v.g.-, son tanto o más importantes que otros manejados por la doctrina clásica.

\section{El concepto de cuenca}

Aunque ya se hayan hecho algunas referencias a este concepto, al considerar la problemática desde la perspectiva tradicional de los ríos internacionales, cabe recordar que la noción de cuenca en cuanto unidad integrada, comienza a ser desarrollada a partir de una fecha relativamente reciente. Los primeros proyectos en gran escala para la explotación común de las aguas de las llamadas cuencas hidrográficas, que significan un marcado progreso en relación a la forma en que tradicionalmente se habían considerado las redes fluviales a los efectos de su uso y aprovechamiento, constituyen una realidad del siglo pasado.

La idea de unidad geoeconómica, también tomó cuerpo en la doctrina, y calificados juristas la desarrollaron. Según Kaufmann, la base de toda regla relativa al uso y aprovechamiento de los ríos internacionales, era el hecho de que el río internacional debía ser considerado "como un conjunto", que implica entre los ribereños una comunidad particular de vecindad, generadora de obligaciones jurídicas mutuas entre los vecinos ${ }^{64}$.

Esta unidad topográfico- geológica denominada cuenca, caracterizada por la concurrencia de un caudal único, determina que un territorio fluvial ríos interiores e internacionales -, sea considerada como comprendiendo toda la zona de influencia del sistema de aguas. Esta circunstancia induce a Cardona a sostener que en el caso de un río internacional pueden distinguirse dos clases de territorios de los Estados limítrofes: "el territorio dividido por el propio río limítrofe y el fluvial que va más allá de éste y comprende no sólo la parte de la cuenca situada dentro del territorio terrestre propio, sino también la ubicada en el territorio vecino" 65 .

La dimensión de la problemática atinente a las cuencas, con frecuencia no ha sido suficientemente valorada debido a que se considera que no afecta a muchas situaciones concretas. El número de cuencas varía según los tratadistas y los informes de algunas organizaciones internacionales tampoco son enteramente coincidentes. Debe tenerse en consideración que el desmembramiento de varios Estados -ex URSS, Yugoslavia, inter aliaconvirtió a muchos cursos de agua internos en "internacionales". Hoy se estiman en alrededor de $300^{66}$.

La noción de cuenca fue discutida por la International Law Association, en la sesión de Nueva York, en $1957^{67}$. Se definió la cuenca de desagüe como "la región situada dentro del territorio de dos o más Estados

\footnotetext{
${ }^{64}$ KAUFMANN. Règles Génèrales du Droit de la Paix, en RCADI, Vol. 54, 1935-IV, pág. 390 .

${ }^{65}$ CARDONA, S. El régimen jurídico de los ríos internacionales, en Revista de Derecho Internacional Público (La Habana), Año XXVIII, T. LVI, pág. 24-29.

66 TANZI, A. Y ARCARI, M. The United Nations Conventions on the Law of International Watercourses. A Framework for Sharing, Kluger Law International, 2001, pág. 4-5.

${ }^{67}$ Doc. OEA/Ser. I/VI, CIJ-75, Rev., pág. 590-592.
} 
y en la cual las corrientes de agua que fluyen por la superficie del terreno, tanto naturales como artificiales, desaguan una línea común divisoria de aguas que termina en una salida común o en salidas comunes al mar o a algún lago o lugar interior desde el cual no hay salida aparente al mar". Hasta mediados de ese siglo, la doctrina poco se había ocupado de las cuencas de desagüe. Asimismo había otorgado preferencia a las aguas superficiales, relegando la cuestión de las aguas subterráneas.

En relación a las cuencas de desagüe se proclaman como principios aplicables, que las mismas deben ser tratadas como unidades integradas; que cada ribereño tiene derecho a una participación razonable y equitativa en los usos provechosos de la cuenca; que cada Estado está obligado a respetar los derechos de los otros Estados ribereños y que ese deber incluía la obligación de evitar que otros, por cuyos actos fuera responsable con arreglo al derecho internacional, violaran los derechos de los demás Estados coribereños.

En 1960, en Hamburgo, la problemática fue incluida en el temario, aprobándose una recomendación acerca del control de la contaminación de las aguas, y de las medidas para solucionar pacíficamente las controversias entre los Estados coribereños de una cuenca de desagüe ${ }^{68}$.

Esta misma institución científica, en las Normas de Helsinki ${ }^{69}$, la definió como "zona geográfica que se extiende por el territorio de dos o más Estados y está demarcada por la línea divisoria de un sistema hidrográfico de aguas superficiales y freáticas que fluyen a una salida común", y calificó de Estado ribereño de una cuenca - llamado también Estado base- a aquel cuyo territorio abarca una porción de la cuenca hidrográfica internacional ${ }^{70}$.

La aceptación de la noción de cuenca, lleva inherente el reconocimiento de derechos y obligaciones recíprocos entre los Estados partes en la cuenca y, sin hesitación, importa ciertas restricciones a la soberanía estatal.

Partiendo de la idea de la "comunidad de intereses" que debe orientar la conducta de los Estados, evitando un proceso de fragmentación de una unidad geográfica, las reglas fundamentales enunciadas como base de una convención en el Acta de Santiago sobre cuencas hidrológicas suscrita por los cancilleres de Argentina y Chile, en junio de 1971, tienen plena validez y aplicabilidad a todas las cuencas. La solidaridad y cooperación amistosa que debe presidir las relaciones mutuas de los países, permite señalar como principios aplicables ${ }^{71}$ :

1. La utilización y explotación de las aguas fluviales y lacustres de una cuenca, debe efectuarse siempre en forma equitativa y razonable.

\footnotetext{
${ }^{68}$ Ibídem, pág. 593-595.

${ }^{69}$ Ibídem, pág. 608-619.

${ }^{70}$ Ibídem, pág. 193.

${ }^{71}$ Boletín de la Integración, Año VI, No 67, julio de 1971, pp. 385-386.
} 
2. Tratándose de ríos internacionales contiguos, el uso y aprovechamiento de las aguas, debe efectuarse previo acuerdo entre los Estados ribereños.

3. Los Estados base tienen derecho a utilizar las aguas de los lagos comunes y ríos internacionales de curso sucesivo dentro de sus respectivos territorios, atendiendo a sus necesidades y a condición de no causar un perjuicio sensible a los otros.

4. Los Estados base tienen la obligación en sus relaciones mutuas, de reparar o compensar los daños y perjuicios ocasionados, y de prevenir cualquier daño futuro.

5. Todo aprovechamiento de las aguas de un lago común o de un río sucesivo por parte de un Estado, deberá previamente ser puesto en conocimiento de los otros Estados cuyo territorio forman parte de la cuenca, facilitándoles el proyecto de la obra, programa de operaciones y demás información que permita evaluar los efectos que producirá en el territorio de estos últimos.

6. Los Estados requeridos deben dar a conocer dentro de un plazo razonable, los aspectos del proyecto o programa que puedan causarle un perjuicio sensible, indicando las razones técnicas y cálculos en que se funda, y cualquier sugerencia tendente a evitar aquel perjuicio.

7. Los conflictos que por estas razones se susciten, deben ser solucionados en forma amistosa y equitativa, sometiéndolos a comisiones técnicas u otros medios pacíficos.

8. Los Estados tienen la obligación de evitar la contaminación de las aguas de los sistemas fluviales o lacustres de la cuenca y preservar los recursos ecológicos de las cuencas comunes, en sus respectivas jurisdicciones.

Cabe destacar que la cuestión de la responsabilidad internacional del Estado por los daños causados por la contaminación de aguas, constituyó una materia muy debatida y aún indefinida, ya sea por la ausencia de normas consuetudinarias o porque no existían muchos antecedentes convencionales. Se planteaban varios interrogantes: ¿A partir de qué grado de contaminación podía considerarse que el daño daba origen a una cuestión de responsabilidad internacional?; ¿Qué debía entenderse jurídicamente por contaminación?; ¿Qué normas jurídicas internacionales debían regir la solución de los litigios suscitados entre los Estados en esta materia?. A estos y otros interrogantes, ha tratado la doctrina de encontrar las respuestas adecuadas.

Según Gunther Handl, tanto del examen de los diversos casos dilucidados ante los tribunales internos e internacionales como de la práctica estatal y de la doctrina en la materia, se podía inferir que el principio de la responsabilidad estatal por la contaminación de los cursos de agua internacionales no había sido un concepto uniformemente desarrollado, aunque destacaba que la responsabilidad por los efectos extraterritoriales en el medio ambiente, requería la convergencia de varios elementos. En primer lugar, la existencia de un daño extraterritorial, en el sentido de un daño 
material producido al medio ambiente de otro Estado. En segundo lugar, que pudiera atribuirse al Estado la actividad causante del daño. En tercer término, el quebrantamiento de una obligación jurídica internacional específica, amén de un uso no razonable de las aguas ${ }^{72}$. Sigue siendo esta una cuestión abierta y motivo de arduos debates en el seno de la CDI.

La amplia problemática derivada de la contaminación de las aguas fluviales comenzó a adquirir gran trascendencia y se insertó también en el marco del Derecho internacional ambiental ${ }^{73}$, sin perjuicio de las facetas específicas que ofrece tal cuestión dentro de la temática en consideración ${ }^{74}$.

\section{La codificación del derecho de los usos de los cursos de agua internacionales para fines distintos de la navegación}

Los intentos de pergeñar una convención o código para la regulación del uso y aprovechamiento de los cursos de agua internacionales con exclusión de la navegación, de aplicación universal, como lo advirtiéramos inicialmente, recién rindieron sus frutos en 1997.

Hubo proyectos de alcance regional, como el elaborado en 1965 para los ríos internacionales en el continente americano, ya comentado, que no llegó a concretarse en un instrumento convencional.

Desde esta perspectiva, ha sido en el viejo continente donde se ha dado un paso significativo con la adopción del Convenio sobre la Protección y Utilización de los Cursos de Agua Transfronterizos y de los Lagos Internacionales, suscripto en Helsinki, en 1992. Fue complementado con dos Protocolos, adoptados en los años 1999 y 2002, respectivamente.

\section{El proyecto de la Comisión de Derecho Internacional y la Convención sobre el Derecho de los Usos de los Cursos de Agua Internacionales para Fines Distintos de la Navegación}

Concluida la tarea precodificadora por la Comisión de Derecho Internacional, la Asamblea General de la ONU, por Resolución 49/52 de diciembre de 1994, dispuso que el Proyecto fuera examinado por el Grupo de Trabajo Plenario de la Sexta Comisión.

72 GUNTHER HANDL. International Liability for the Pollution of International Watercourses: Balancing Interests, en Canadian Yearbook of International Law, Vol. XIII, 1975, pág. 192-193.

73 REY CARO, E. J. Derecho Internacional Ambiental, en Estudios de Derecho Internacional, Córdoba (Argentina), 1982, pág. 71-108; CHIESA, N. E. La protección del medio ambiente y el derecho internacional, en Revista de Derecho Internacional y Ciencias Diplomáticas, Rosario (Argentina), No. 46-47, 1977-1978, pág. 31-40 y de la misma autora "Cuestión ambiental: derecho y política internacional", en Revista de Derecho Internacional y Ciencias Diplomáticas, Rosario (Argentina), No. 48-49, 19791980, pág. 39-56.

74 CHIESA, N.E. La problemática estructural, técnica y jurídico-institucional del aprovechamiento compartido del recurso hidroeléctrico internacional (No marítimo), op. cit., pág. 114-120; NAVARRO VEGA, I. La contaminación de los ríos internacionales, en Estudios sobre Derecho Internacional, Asociación Mexicana de Derecho Internacional, México, 1975, pág. 47-70. 
Este Grupo, tuvo como mandato elaborar una convención marco sobre el derecho de los usos de los cursos de agua internacionales para fines distintos de la navegación, celebrando dos períodos de sesiones. Para el examen del texto del proyecto de Convención, se designaron coordinadores de consultas oficiosas que se ocuparon de determinados artículos del instrumento ${ }^{75}$.

El Grupo de Trabajo y el Comité de Redacción estudiaron una gran variedad de propuestas formuladas por los Estados en forma individual o conjunta, sobre uno o varios de los dispositivos, presentadas durante las reuniones de 1996 y $1997^{76}$. Hubo cuestiones conflictivas, como la del alcance del principio de la utilización equitativa y sobre los mecanismos de solución de controversias, entre otras, que sólo fueron superadas luego de arduas negociaciones ${ }^{77}$.

Finalmente, por Resolución 51/229 de la Asamblea General, se aprobó el texto de la Convención.

Como ya lo señaláramos, los estudios de factibilidad para la codificación de la problemática se iniciaron con la aprobación por la Asamblea General de la ONU, de la Resolución 1401(XIV).

En 1970, la Asamblea General, a propuesta de Finlandia, aprobó la Resolución 2669(XXV), titulada Desarrollo Progresivo y Codificación de las normas de Derecho Internacional sobre los Cursos de Agua Internacionales, recomendando a tales efectos la iniciación de las tareas por parte de la Comisión de Derecho Internacional ${ }^{78}$.

\section{La convención de 1997}

El Preámbulo de este instrumento debió ser elaborado por el Grupo de Trabajo y el Comité de Redacción, en razón de que el Proyecto de la CDI, como es usual, sólo contenía la parte sustantiva de la materia que podría llegar a convertirse en un acuerdo o tratado.

La Parte I, que obra como introductoria, contiene cuatro artículos.

El primero de ellos, fija el ámbito de aplicación de la Convención. Está concebido en los siguientes términos:

"1. ... se aplica a los usos de los cursos de agua internacionales y de sus aguas para fines distintos de la navegación y a las medidas de protección, preservación y ordenación relacionadas con los usos de los cursos de agua y de sus aguas".

Siguiendo una metodología propia de las principales convenciones codificadoras del derecho internacional, el artículo 2, establece el alcance de los términos utilizados en el instrumento. Al respecto, prescribe:

"a) Por "curso de agua" se entenderá un sistema de aguas superficiales y subterráneas que, en virtud de su relación física, constituyen un conjunto unitario y normalmente fluyen a una desembocadura común;

\footnotetext{
${ }^{75}$ ONU, Asamblea General, Doc. A/51/869, 11 de abril de 1997, pág. 1-2.

${ }^{76}$ Ibídem, pág. 2-5.

${ }^{77}$ TANZI, A. Y ARCARI, M. Op. cit., pág. 140.

${ }^{78}$ Resoluciones aprobadas por la Asamblea General durante su vigésimo quinto período de sesiones, pág. 135.
} 
b) Por "curso de agua internacional" se entenderá un curso de agua, algunas de cuyas partes se encuentran en Estados distintos;

c) Por "Estado del curso de agua" se entenderá un Estado Parte en la presente Convención en cuyo territorio se encuentra parte de un curso de agua internacional o una Parte que sea una organización de integración económica regional en el territorio de uno o más de cuyos Estados miembros se encuentra parte de un curso de agua internacional";

La Subcomisión que designó la CDI, en cumplimiento de la recomendación efectuada en la Resolución 3071 (XXVIII) de la Asamblea General, destacó que uno de los primeros problemas a dilucidar en el estudio del tema era el alcance que debía atribuirse a la expresión cursos de agua internacionales - habida cuenta de que en muchos tratados se habían utilizado las expresiones cuenca fluvial, cuenca del río o cuenca hidrográfica, inter alia-, para definir el ámbito de aplicación.

Debe destacarse que el Proyecto de la CDI, se fundó únicamente en la elaboración de un instrumento en el que podrían ser partes los Estados. Ésta fue una innovación del Grupo de Trabajo designado por la Asamblea General para examinar el Proyecto.

No constituye una novedad el hecho de que una organización internacional gubernamental pudiera ser parte en un tratado vinculado con el régimen de un río o cuenca internacional. La Convención limita la posibilidad de ser parte únicamente a las organizaciones de integración económica regional. Tal podría ser el caso de la Comunidad Económica Europea - hoy Unión Europea - y eventualmente del Mercosur, aunque en relación a este último ente, estimamos que por el momento no se cumpliría con el requisito de la transferencia de competencias en la materia por parte de los Estados miembros.

El Capítulo introductorio contiene otros dos dispositivos, referidos a los acuerdos de curso de agua (artículo 3) y a las partes de un curso de agua (artículo 4).

En relación a los acuerdos de curso de agua, el art. 3 la Convención, dispone:

"1. Salvo acuerdo en contrario, nada de lo dispuesto en la presente Convención afectará a los derechos u obligaciones de un Estado del curso de agua derivados de acuerdos que hayan estado en vigor respecto de la fecha en que se haya hecho parte en la presente Convención".

El Artículo 4 de la Convención, prescribe:

"1. Todo estado del curso de agua tiene derecho a participar en la negociación de cualquier acuerdo del curso de agua que se aplique a la totalidad de ese curso de agua internacional y a llegar a ser parte él, así como a participar en cualesquiera consultas sobre el particular.

2. El Estado del curso de agua cuyo uso de un curso de agua internacional pueda resultar afectado de manera sensible por la ejecución de un acuerdo del curso de agua propuesto que solamente se aplique a una parte del curso de agua o a un proyecto, programa o uso determinado tendrá derecho a participar en las consultas sobre tal acuerdo y, cuando proceda, a negociar de buena fe para hacerse parte en él, en la medida en que su uso resulte afectado por ese acuerdo". 
La Parte II de la Convención, constituye desde nuestra perspectiva, la médula o el eje del instrumento, ya que contiene los principios generales aplicables al uso y aprovechamiento de los cursos de agua.

El Artículo 5, referido a la "Utilización y participación equitativa y razonable", reproduce textualmente la propuesta de la CDI:

\begin{abstract}
"1. Los Estados del curso de agua utilizarán en sus territorios respectivos un curso de agua internacional de manera equitativa y razonable. En particular, los Estados del curso de agua utilizarán y aprovecharán un curso de agua internacional con el propósito de lograr la utilización óptima y sostenible y el disfrute máximo compatibles con la protección adecuada del curso de agua, teniendo en cuenta los intereses de los Estados del curso de agua de que se trate.

2. Los Estados del curso de agua participarán en el uso, aprovechamiento y protección de un curso de agua internacional de manera equitativa $y$ razonable. Esa participación incluye tanto el derecho de utilizar el curso de agua como la obligación de cooperar en su protección y aprovechamiento, conforme a lo dispuesto en la presente Convención."
\end{abstract}

En 1987, la CDI dio forma definitiva al texto del artículo 5 actual, cuya redacción pareciera poner más énfasis en las obligaciones de los Estados del curso de agua ${ }^{79}$.

La palabra participación, refleja en forma apropiada el aspecto dual que encierra el derecho de un Estado del curso de agua internacional. Se trata de un derecho de uso, pero también trae aparejada la obligación de contribuir a la ordenación y la conservación del sistema del curso de agua para una distribución óptima de los beneficios.

La Declaración sobre uso industrial y agrícola de los ríos internacionales adoptada en Montevideo, en 1933, había establecido entre sus principios que los Estados tenían el derecho exclusivo de aprovechar para tales fines, la margen que se encuentra bajo su jurisdicción de las aguas de los ríos internacionales, derecho que estaba condicionado en su ejercicio por la necesidad de no perjudicar el igual derecho que correspondía al Estado vecino en la margen de su jurisdicción, siendo aplicable este principio tanto a los ríos sucesivos como a los contiguos. También se encuentra incorporado este principio en el proyecto de convención elaborado por el Comité Jurídico Interamericano en 1965, sobre utilización de las aguas de los ríos y lagos internacionales para fines industriales y agrícolas ${ }^{80}$.

Importantes conferencias mundiales que se abocaron a esta materia, igualmente reiteraron tal principio. Es el caso del Principio 21 aprobado en la Conferencia de Naciones Unidas sobre el Medio Humano, en 1972 ${ }^{81}$, y la

\footnotetext{
79 Informe de la CDI sobre la labor realizada en su 39 período de sesiones, pág. 55.

80 COMITÉ JURÍDICO INTERAMERICANO. Recomendaciones e Informes, en Documentos Oficiales, Vol. IX, pág. 72-75

${ }^{81}$ Informe de la Conferencia de las Naciones Unidas sobre el Medio Humano, pág. 4-6.
} 
recomendación sobre ordenación y utilización de los recursos hidráulicos, incluida en el Plan de Acción de Mar del Plata, en $1977^{82}$.

El artículo 5 de la Convención es uno de los más importantes, por enunciar los derechos y obligaciones básicos de los Estados en el uso y aprovechamiento de los cursos de agua internacionales. El párrafo 1, incorpora la regla de la utilización equitativa y razonable, que conlleva la obligación correlativa de no privar a los otros Estados del curso de agua de igual derecho. El párrafo 2, desarrolla aquella regla básica, fijando los objetivos que deben tener en consideración los Estados del curso de agua. Como destacara el comentario de la CDI, lograr la utilización óptima y el disfrute máximo no importa conseguir el uso máximo, el uso tecnológicamente más eficiente ni, incluso, el uso pecuniariamente más lucrativo. Significa más bien lograr el disfrute máximo posible para todos los Estados del curso de agua y la mayor satisfacción posible para todos los Estados del curso de agua, con el mínimo detrimento para cada uno de ellos, objetivo que debe estar subordinado a la protección adecuada del curso de agua. Dicha protección comprende las medidas relativas a la conservación y la seguridad y las de control, como las conducentes a regular la corriente, luchar contra las inundaciones, la contaminación y la erosión, aliviar las sequías y prevenir la intrusión de agua salada.

El párrafo 2, se refiere a la participación equitativa, principio éste que se deriva de la regla de la utilización equitativa. Exige que los Estados del curso de agua cooperen para alcanzar el disfrute máximo para cada uno de ellos, contribuyendo simultáneamente a mantener un reparto equitativo de los usos y dar una protección adecuada a los Estados del curso de agua y al propio curso de agua internacional. La última parte del párrafo, destaca el carácter positivo de la participación equitativa, que tanto incluye el derecho de utilizar el curso de agua - derecho este que como lo señaláramos, fue reconocido tempranamente por la práctica y la jurisprudencia internacional, como la obligación de cooperar con los demás Estados del curso de agua en su protección y aprovechamiento. No obstante, el deber de cooperar ha sido tratado en la Convención en forma independiente ${ }^{83}$.

El artículo 6 de la Convención aborda la cuestión de los factores pertinentes en una utilización equitativa y razonable. Ellos son, entre otros:

"a) Los factores geográficos, hidrográficos, hidrológicos, ecológicos y otros factores naturales;

b) Las necesidades económicas y sociales de los Estados del curso de agua de que se trate;

c) La población que depende del curso de agua en cada Estado del curso de agua;

d) Los efectos que el uso o los usos del curso de agua en uno de los Estados del curso de agua produzcan en otros Estado del curso de agua;

\footnotetext{
82 Organización de las Naciones Unidas. Conferencia de las Naciones Unidas sobre el Agua, Consolidación de las Recomendaciones de Acción (Doc. E/CONF.70/9), pág 10. Informe de la CDI sobre la labor realizada en su 39 período de sesiones, pág. 56 y ss.

${ }^{83}$ Informe de la CDI sobre la labor realizada en su 39 período de sesiones, pág. 56 y ss.
} 
e) Los usos actuales y potenciales del curso de agua;

f) La conservación, la protección, el aprovechamiento y la economía en la utilización de los recursos hídricos del curso de agua y el costo de las medidas adoptadas al efecto;

g) La existencia de alternativas, de valor comparable, respecto del uso particular actual previsto".

El dispositivo en consideración agrega en el párrafo 2, que:

"En la aplicación del artículo 5 o del párrafo 1 del presente artículo, los Estados del curso de agua de que se trate celebrarán, cuando sea necesario, consultas con un espíritu de cooperación", y el párrafo 3 que: "El peso que se asigne a cada factor dependerá de su importancia en comparación con la de otros factores pertinentes. Para determinar que constituye una utilización equitativa y razonable, se examinarán conjuntamente todos los factores pertinentes y se llegará a una conclusión sobre la base del conjunto de esos factores".

El artículo 5 de la Convención tiene el alcance de norma general y flexible. La instrumentación debe tener en consideración múltiples factores que los Estados del curso de agua ponderarán en cada caso. Dichos factores constituyen la materia que regula el artículo 6, cuya lista no tiene carácter taxativo. La diversidad de los cursos de agua y la diferente naturaleza de las necesidades a satisfacer por los Estados del curso de agua, impedían la elaboración de un catálogo completo y excluyente de dichos factores y circunstancias. Tampoco en su enunciado hay un orden de prelación, ni se consagran prioridades. El grado de importancia dependerá de las características de cada curso de agua y de las políticas fluviales de los Estados del curso, respetando siempre el principio de la utilización equitativa y razonable.

De acuerdo con el apartado d), no se otorga prioridad a ninguno de los usos existentes o potenciales, pudiendo ser pertinente en cada caso, los dos factores o sólo uno de ellos.

En cuanto al apartado e) el alcance de cada término está limitado por el que otorga a ellos otras disposiciones de la Convención. El término "aprovechamiento", expresa los proyectos o programas para sacar provecho de un curso de agua o para aumentar el provecho que se puede obtener de dicho curso, mientras que la expresión economía en la utilización contempla la posibilidad de evitar un inútil despilfarro del agua ${ }^{84}$ (242).

El apartado f) contempla la necesidad de indagar sobre la existencia de medios alternativos de satisfacer las necesidades que son o podrían ser satisfechas por usos existentes o previstos. Así las alternativas podrían ser no sólo otras fuentes de abastecimiento de agua, sino en otros medios de satisfacer esas necesidades, como las fuentes alternativas de energía u otros medios de transporte. La expresión de valor correspondiente, sugiere la idea de viabilidad, factibilidad y relación costo -eficacia, generalmente comparables.

${ }^{84}$ Ibídem. Pág. 68 
La obligación de efectuar consultas en los casos a que se refiere el párrafo 2 - utilización, aprovechamiento o protección de un curso de agua internacional para enfrentar las situaciones que han generado la necesidad de las consultas -, se inserta en el ámbito más amplio de la obligación general de cooperación, que ha sido regulada en el artículo 7 de la Convención.

Un catálogo de factores pertinentes se incluyó ya en las Normas de Helsinki sobre los usos de las aguas de los ríos internacionales de 1966, que en su mayor parte han sido recogidas en el precepto en consideración de la Convención ${ }^{85}$.

La obligación de no causar daños sensibles ha sido receptada en el artículo 7 de la Convención:

"1. Los Estados del curso de agua, al utilizar un curso de agua internacional en sus territorios, adoptarán todas las medidas apropiadas para impedir que se causen daños sensibles a otros Estados del curso de agua".

Este dispositivo, con algunas modificaciones que no alteran el espíritu de la propuesta de la CDI, recoge un principio cardinal en la materia. Por otra parte, se trataría de una obligación de resultado ${ }^{86}$.

La noción de daño o perjuicio apreciable vino a establecer un equilibrio entre aquellas doctrinas que proclamaron el derecho del Estado ribereño de utilizar y disponer de la parte del curso de agua que discurre por su territorio sin limitación alguna, cuyo arquetipo fue la doctrina Harmon, con otras formulaciones también absolutas que proscribían las actividades de los Estados del curso que causaren cualquier perjuicio a otro Estado del mismo curso de agua. Esta fórmula ha sido adoptada en algunos tratados referidos a la protección del curso de agua contra la contaminación, sin que se haya generalizado.

Existió en la CDI la convicción de que la máxima sic utere tuo ut alienum non laedas debía ocupar un lugar de privilegio en el proyecto ya que la obligación de no causar daños a otros Estados constituía un principio generalmente aceptado de derecho internacional. Como lo señaláramos en su oportunidad, tempranamente la jurisprudencia internacional receptó tal principio en el affaire de la Fundición Trail.

Es indiscutible que el uso o aprovechamiento que pudiera efectuar un Estado ribereño de las aguas del curso de agua internacional difícilmente no traiga aparejada al menos una molestia o ligero perjuicio a los otros Estados del curso ${ }^{87}$. De allí que para que puedan considerarse afectados los intereses jurídicos de un Estado del curso de agua internacional, según la concepción predominante, el daño tiene que alcanzar cierta significación. Debe destacarse que la modificación de un curso de agua internacional por uno de

${ }^{85}$ ILA. Report of the Fifty Second Conference, London, 1967, pág. 488.

86 CASTILlo DAUDI, M. La protección y preservación de cursos de agua internacionales: el Convenio sobre el derecho de los usos de los cursos de agua internacionales para fines distintos de la navegación de 21 de mayo de 1997 , en Anuario de Derecho Internacional, Universidad de Navarra, Vol. XV, 1999, pág. 139.

87 BARBERIS, JULIO A. Droits et obligations des pays riverains des fleuves internationaux, Acadèmie de Droit International de La Haye, Dordrecht, 1991, pág. 32. 
los Estados del curso de agua no es por sí sola ilícita. Lo que el derecho internacional prohíbe es que tal cambio cause un perjuicio apreciable, sea modificando el curso de agua, el volumen de sus aguas o la calidad de ellas, o en cualquier otra forma.

En la práctica convencional internacional se han utilizado diversos calificativos para condicionar el daño. Se habla de sustancial, sensible, significativo, apreciable o notable, entre otros, pudiendo observarse variaciones terminológicas según la lengua empleada.

El principio incorporado en el artículo 7 de la Convención, había tenido una amplia recepción en diversos instrumentos internacionales suscritos por la República Argentina en la década del 70, que frecuentemente son invocados en la doctrina, tales como el Acta de Asunción de 1971, suscrita por los Estados de la Cuenca del Plata y el Acta de Santiago sobre cuencas hidrográficas y la Declaración de Buenos Aires de junio y julio del mismo año. El Tratado sobre el Río de la Plata y su frente marítimo de 1974, lo menciona reiteradamente ${ }^{88}$. En todos ellos se hace referencia al derecho de cada Estado de aprovechar las aguas de los cursos de agua pertinentes de conformidad con sus necesidades, a condición de no causar un perjuicio "sensible" a los otros Estados del curso, cuenca o río internacional.

El artículo 8, consagra la obligación general de cooperar:

\begin{abstract}
"1. Los Estados del curso de agua cooperan sobre la base de los principios de la igualdad soberana, la integridad territorial, el provecho mutuo y la buena fe a fin de lograr una utilización óptima y una protección adecuada de un curso de agua internacional.

2. Los Estados del curso de agua, al determinar las modalidades de esa cooperación, podrán considerar la posibilidad de establecer las comisiones o los mecanismos conjuntos que consideren útiles para facilitar la cooperación en relación con las medidas y los procedimientos en la materia, teniendo en cuenta la experiencia adquirida mediante la cooperación en las comisiones y los mecanismos conjuntos existentes en diversas regiones".
\end{abstract}

La obligación de cooperar guarda una muy estrecha relación y aparece inseparablemente entrelazado con las normas reconocidas en los artículos 5 y 7 de la Convención, y se enmarca también en una obligación más amplia y general de cooperar receptada en la Carta de las Naciones Unidas, la Resolución 2625 (XXVI) de la Asamblea General de las Naciones Unidas, conocida también como Declaración sobre los Principios de Derecho Internacional Referentes a las Relaciones de Amistad y a la Cooperación entre los Estados de conformidad con la Carta de las Naciones Unidas, y otros instrumentos internacionales. El segundo Relator Especial recordaba que diversos órganos internacionales habían adoptado en los últimos años una postura muy firme y definida en favor del fortalecimiento de la cooperación entre los Estados de un curso de agua internacional con el propósito de obtener una utilización más racional de los recursos hidráulicos compartidos del mundo. Éstos, según el Comité de Recursos Naturales del

\footnotetext{
${ }^{88}$ REY CARO, ERNESTO J. Regulación jurídica del aprovechamiento de los cursos de agua internacionales, en Jurisprudencia Argentina, Bs.As., junio 8 de 1977, pág. 9.
} 
Consejo Económico y Social de las Naciones Unidas, ofrecían "una oportunidad única para fomentar la amistad entre los países. El aprovechamiento óptimo de esas aguas exige que se tomen medidas prácticas de asociación internacional, de las que puedan beneficiarse todas las partes de forma tangible y visible mediante la acción concertada. El agua es un recurso vital, cuyos beneficios pueden multiplicarse a través de esfuerzos comunes y cuyos efectos perjudiciales pueden evitarse o eliminarse mediante actos de colaboración...Un rasgo característico de las medidas internacionales adoptadas en los últimos tiempos para desarrollar los recursos hidráulicos ha sido la ampliación del alcance y diversidad de las actividades que realizan las partes para aprovechar las aguas internacionales" 89 .

Entre las recomendaciones adoptadas por la Conferencia de las Naciones Unidas sobre el Agua, en 1977, se destaca la Número 90 referida al desarrollo de los recursos hídricos compartidos, declarando la necesidad de que los Estados cooperaran en reconocimiento de la creciente interdependencia en materia económica, ambiental y geográfica a través de las fronteras internacionales y que dicha cooperación debía realizarse sobre la base de la igualdad, soberanía $e$ integridad territorial de todos los Estados ${ }^{90}$.

Evensen propuso un dispositivo que incorporaba el principio de cooperación pero muy atenuado, pues prescribía que los Estados del sistema que compartían el sistema de un curso de agua internacional cooperarían "en la medida de lo posible", respecto de los usos y programas relacionados con el sistema, a fin de lograr la utilización, protección y el control óptimos del sistema del curso de agua ${ }^{91}$.

McCaffrey propuso una fórmula más absoluta, que no dejaba tanto margen para la discrecionalidad de los Estados del curso de agua. "Todos los Estados - decía el artículo 10 de su proyecto -, cooperarán de buena fe con otros Estados interesados en sus relaciones referentes a los cursos de agua internacionales y en el cumplimiento de sus obligaciones respectivas en virtud de los presentes artículos" 92.

En el marco de la obligación de cooperar, la Convención ha institucionalizado en el artículo 9 que el "intercambio regular de datos e información", que los Estados del curso de agua pudieran razonablemente disponer sobre el estado del curso de agua, previendo el mismo dispositivo el procedimiento a seguir en caso de que el Estado requerido no pudiera

\footnotetext{
89 Tercer informe sobre el derecho de los usos de los cursos de agua internacionales para fines distintos de la navegación, Op. cit., pág. 54.

90 Naciones Unidas, Conferencia de las Naciones Unidas sobre el Agua, Op. cit., pág. 35. Recomendación 85 .

91 Primer informe sobre el derecho de los usos de los cursos de agua internacionales para fines distintos de la navegación, Op. cit., pág. 42.

92 Tercer informe sobre el derecho de los usos de los cursos de agua internacionales para fines distintos de la navegación (Doc. A/CN.4/406).
} 
disponer de la información pertinente, como así también la utilización de la información por los otros Estados del curso de agua:

$" l$. De conformidad con el artículo 8, los Estados del curso de agua intercambiarán regularmente los datos y la información que estén fácilmente disponibles sobre el estado del curso de agua, en particular los de carácter hidrológico, meteorológico y ecológico y los relativos a la calidad del agua, así como las previsiones correspondientes.

2. El Estado del curso de agua al que otro Estado del curso de agua le pida que proporcione datos e información de los que estén fácilmente disponibles hará lo posible por atender esta petición, pero podrá exigir que el Estado solicitante pague los costos razonables de la recopilación, y en su caso, el procesamiento de esos datos e información.

3. Los Estados del curso de agua harán lo posible por reunir y, en su caso, procesar los datos y la información de manera que se facilite su utilización por los otros Estados del curso de agua a los que sean comunicados".

Este precepto reproduce casi textualmente la propuesta de la CDI.

El articulo 9 confía a los Estados del curso de agua la forma de determinar los procedimientos de reunión e intercambio de datos que mejor se adapten a las características del curso de agua, contemplándose también el caso de que el Estado requerido no posea los medios necesarios, económicos o de otra naturaleza, para suministrar la información. No puede exigirse que los Estados, suministren datos e información que razonablemente no dispongan, o si no se les compensara los gastos de obtención y procesamiento.

Esta última hipótesis ha sido contemplada expresamente en el artículo 31 de la Convención, en cuanto establece que:

"Nada de lo dispuesto en la presente Convención obliga a ningún Estado del curso de agua a proporcionar datos o información que sean vitales para su defensa o seguridad nacionales. No obstante, todo Estado del curso de agua cooperará de buena fe con los demás Estados del curso de agua para proporcionar toda la información que sea posible según las circunstancias".

También se incluye la información que puede caracterizarse de secreto comercial", o estar vinculada con otras cuestiones como la planificación económica o las condiciones socio-económicas. En todo caso el principio rector debía ser siempre la cooperación de buena $\mathrm{fe}^{93}$.

El capítulo de la Convención sobre los "Principios Generales", se cierra con un dispositivo - artículo 10-, referido a las relaciones entre los usos, que prevé la cuestión de la prioridad entre los usos y el caso de conflicto entre varios usos de un curso de agua internacional:

"1. Salvo acuerdo o costumbre en contrario, ningún uso de un curso de agua internacional tiene en sí prioridad sobre otros usos.

2. El conflicto entre varios usos de un curso de agua internacional, se resolverá sobre la base de los Artículos 5 a 7, teniendo especialmente en cuenta la satisfacción de las necesidades humanas esenciales".

${ }^{93}$ Anuario de la CDI, 1987, Vol. II, Primera parte, pág. 46. 
Excluido el uso navegación del ámbito de aplicación del proyecto de la CDI, excepto en la medida en que los otros usos afecten a la navegación o resulten afectados por ésta, como prevé el artículo 4 de la Convención, la norma en examen sienta el principio de igualdad de usos.

La preferencia del uso navegación sobre los otros usos predominó en la práctica convencional hasta el momento en que estos últimos adquirieron tanta o más importancia que aquel uso tradicional por obra de los adelantos tecnológicos o de la explosión demográfica. Según Schwebel, el orden de prioridad constituye "la interrelación jurídica clave entre los usos distintos a la navegación y los usos para la navegación en el derecho internacional general", obedeciendo aquel desplazamiento a la acogida por los Estados del curso de agua de las doctrinas de utilización equitativa y de protección ambiental ${ }^{94}$. La International Law Association adoptó esta postura en el artículo VI de las Normas de Helsinki: "Un uso o categoría de usos no tiene derecho a ninguna preferencia inherente respecto de otro uso o categoría de usos" $^{95}$.

La Convención ha dedicado la Parte III a regular el procedimiento a seguir cuando los Estados del curso de agua proyecten medidas que pudieran causar efectos en la situación, característica o estado del curso de agua internacional.

Para este caso ha establecido en el artículo $11^{96}$ el principio general de la obligación de intercambiar información y realizar consultas ${ }^{97}$, que como ya destacáramos se trata de una hipótesis diferente a la regulada en el artículo 9 de la Convención.

Esta cuestión ha sido ampliamente debatida en la doctrina y ha sido materia de numerosos acuerdos internacionales que han adoptado al respecto soluciones muy diversas.

Reconocido el derecho del Estado de aprovechar y usar la aguas de un curso de agua internacional localizadas en su territorio, como lo consagra expresamente el artículo 7 de la Convención, dicho uso y aprovechamiento está condicionado por otro principio cual es el de no causar un perjuicio apreciable a los otros Estados del curso de agua. Pero, a su vez, la responsabilidad subsiguiente y la indemnización pecuniaria, como destaca Jiménez de Aréchaga ${ }^{98}$, no constituye la solución adecuada para ninguno de los Estados involucrados, ya que la obligación de satisfacer una reparación

\footnotetext{
${ }^{94}$ Tercer informe sobre el derecho de los usos de los cursos de agua internacionales para fines distintos de la navegación, Op. cit., pág. 326.

${ }_{95}^{95}$ ILA, Report of the Fifty-second Conference. Op. cit., pág. 14.

96 Artículo 11: Los Estados del curso de agua intercambiarán información y se consultarán acerca de los posibles efectos de las medidas proyectadas sobre el estado de un curso de agua internacional.

${ }^{97}$ REY CARO, ERNESTO J. La consulta previa en el aprovechamiento de los recursos naturales compartidos. Los ríos internacionales, en Cuadernos de Derecho Público de la Universidad de los Andes, $\mathrm{N}^{\circ}$ 4, 1978, pp. 9-38.

98 JIMENEZ DE ARECHAGA, E. El Derecho Internacional Contemporáneo, Madrid, 1980, pág. 231-232.
} 
monetaria o de otra índole o la restitución del statu quo ante, puede constituir una carga difícil de sobrellevar o bien de imposible cumplimiento.

De allí entonces, la importancia de prevenir los daños o perjuicios mediante el reconocimiento de la necesidad de que los Estados del curso de agua internacional adopten determinadas medidas antes de emprender usos o aprovechamientos que pudieran causar un perjuicio sensible o apreciable.

Entre tales medidas, la práctica convencional ha consagrado la notificación, la información, la consulta o el acuerdo previo. No obstante es justo reconocer que no todas estas medidas o la obligación de adoptarlas por los Estados del curso de agua internacional, han sido reconocidas como la expresión de una norma del derecho internacional general aplicable en esta materia.

Ello acontece con el acuerdo previo, que ha sido incorporado en algunos tratados como requisito para el emprendimiento de un uso o aprovechamiento de un curso de agua internacional. En el caso del lago Lanoux, el Tribunal, sostuvo que todo Estado tiene derecho de realizar en su territorio las obras públicas que considere conveniente sobre los cursos de aguas que pasan al Estado vecino, a condición de que no sufra alteración el volumen de aguas que debe percibir este último, pero que la necesidad de un acuerdo previo entre los Estados ribereños para el aprovechamiento de la fuerza hidráulica, no tenía asidero ni como norma consuetudinaria, ni como principio general del derecho ${ }^{99}$.

La Declaración de Asunción, sobre aprovechamiento de los ríos internacionales, aprobada en la IV Reunión de Cancilleres de la Cuenca del Plata de 1971, ya citada, estableció que en los ríos internacionales contiguos, el aprovechamiento de sus agua debía realizarse mediante "acuerdo" previo ${ }^{100}$ (271), fórmula esta que también fue receptada en el Acta de Santiago sobre cuencas hidrográficas, suscrita entre Argentina y Chile en el mismo año, aunque este último instrumento institucionalizó la "información" previa para el aprovechamiento de las aguas de un lago común o de un río sucesivo ${ }^{101}$ (272). Asimismo este último acuerdo, previó en la regla 6 un procedimiento que las partes se comprometían a volcar expresamente en un tratado, a regir para la segunda hipótesis.

El Proyecto de Convención elaborado por el Comité Jurídico Interamericano, sobre utilización de las aguas de los ríos y lagos internacionales para fines industriales y agrícolas, estableció que todo Estado que proyecte realizar obras de aprovechamiento en un río o lago internacional debía notificar previamente a los demás Estados ribereños, notificación que debía ser escrita e ir acompañada de la documentación técnica necesaria para poder determinar los efectos de dichas obras ${ }^{102}$.

\footnotetext{
99 Anuario de la CDI, 1974, Vol. II, Segunda parte, pág. 210.

${ }^{100}$ Ibídem, pág. 351 .

101 Ibídem, pág. 381-382.

102 COMITÉ JURÍDICO INTERAMERICANO. Recomendaciones e Informes, en Documentos Oficiales, Vol. IX, pág. 72-75
} 
Sobre la base de la propuesta de artículos que efectuara el Relator Especial McCaffrey en su tercer informe, a los cuales se le introdujeron varias modificaciones, la Comisión ha regulado el procedimiento a observar por los Estados de un curso de agua internacional para el caso que se proyecten medidas que pudieran producir efectos sobre aquél, cuestión esta de la que se ocupan los artículos 12 al 19 de la Convención.

El artículo 12, se refiere a la notificación de las medidas proyectadas que puedan causar un efecto perjudicial; el artículo 13, al plazo para responder a la notificación; el artículo 14, a las obligaciones del Estado notificante durante el plazo de respuesta; el artículo 15 , a la respuesta a la notificación; el artículo 16, a la falta de respuesta a la notificación; el artículo 17, a las consultas y negociaciones sobre las medidas proyectadas; el artículo 18, a los procedimientos aplicables a falta de notificación; y el artículo 19, a la ejecución de las medidas proyectadas en caso de urgencias.

Las etapas a seguir por los Estados del curso de agua pueden sintetizarse de la siguiente forma:

1) El Estado que proyecte ejecutar o permitir la ejecución de medidas que puedan causar efectos perjudiciales apreciables a los otros Estados del curso de agua, debe notificar en forma oportuna estas, acompañando los datos técnicos y la información disponible que les permita evaluar los posibles efectos de las medidas proyectadas (artículo 12);

2) Salvo acuerdo en contrario, el Estado que practica la notificación, dará a los Estados notificados un plazo de seis meses para estudiar y evaluar los posibles efectos y comunicarles a aquel sus conclusiones (artículo 13);

3) Durante este plazo el Estado notificante debe cooperar con los otros Estados notificados, facilitándoles los datos e información suplementarios necesarios, y se abstendrá de ejecutar las medidas proyectadas sin el consentimiento de los Estados a los que se le haya hecho la notificación (artículo 14);

4) Si el Estado (o Estados), al que se haya efectuado la notificación llegara a la conclusión de que las medidas proyectadas serían incompatibles con el principio de la utilización y participación equitativas y razonables, o que pudieran causar un perjuicio apreciable, debe comunicar dentro del plazo de seis meses referido esa conclusión, acompañando los elementos en que la misma se fundamente (artículo 15);

5) Si no se diera respuesta a la notificación dentro de los seis meses, el Estado notificante puede iniciar la ejecución de las medidas proyectadas (artículo 16);

6) En el caso de que el o los Estados notificados efectuaren la comunicación prevista en el artículo 15, el Estado notificante y el Estado autor de la comunicación deberán iniciar consultas y negociaciones para llegar a una solución equitativa, negociación que se llevará a cabo con observancia del principio de buena fe. Mientras duren las consultas y negociaciones, el Estado notificante no ejecutará ni permitirá la ejecución de las medidas proyectadas, por un plazo que no excederá de seis meses, si 
el Estado al que se la haya hecho la notificación lo solicita en el momento en que haga la comunicación (artículo 17);

7) En el caso de que un Estado del curso de agua "tenga razones graves para creer que otro Estado del curso de agua proyecta tomar medidas que puedan causarle un efecto perjudicial apreciable", podrá pedir a ese otro Estado que se le notifique las medidas proyectadas. Si el Estado requerido considera que no es pertinente esta notificación lo comunicará a aquel Estado fundando esta conclusión. En caso de desacuerdo, los Estados involucrados deberán iniciar consultas y negociaciones en los términos previstos en el artículo 17, debiendo el Estado que proyecte tomar las medidas abstenerse de ejecutarlas ni permitir su ejecución en el mismo plazo y en las condiciones que prescribe este artículo (artículo 18);

8) $\mathrm{Si}$ razones de extrema urgencia "para proteger la salud y la seguridad públicas y otros intereses igualmente importantes", así lo requieren, el Estado que proyecte las medidas puede iniciar inmediatamente su ejecución mediante una declaración formal sobre la urgencia de las medidas a los demás Estados del curso de agua que pudieran resultar afectados, no eximiendo al Estado que inicia la ejecución de las medidas, del cumplimiento de lo dispuesto en los artículos 5 y 7 de la Convención y de iniciar consultas y negociaciones (artículo 19).

Cuando se debatió esta cuestión en la CDI, hubo consenso en cuanto a que este procedimiento debía garantizar en la medida de lo posible, que un Estado al utilizar un curso de agua internacional, no produzca un menoscabo a los otros estados del curso, y que no debía otorgarse a éstos últimos un derecho de veto, real o efectivo sobre las actividades planificadas por el primero.

La cuestión se centró fundamentalmente en establecer un justo equilibrio entre los derechos del Estado que pretende efectuar un uso o aprovechamiento del curso de agua y los derechos de los otros Estados del curso, equilibrio este que en nuestro entender ha sido logrado.

La problemática medio-ambiental durante los debates en el seno de la CDI, estuvo presente en los informes de tres Relatores Especiales ${ }^{103}$.

Finalmente, la Comisión adoptó algunos criterios, sobre la base del extenso estudio y proyecto de artículos propuestos por el Relator Especial McCaffrey ${ }^{104}$, que fueron recogidos por la Convención, con modificaciones no substanciales.

103 CARDONA LloRENS, J. La protección del medio ambiente de los cursos de agua internacionales en los trabajos de la Comisión de Derecho Internacional, en Problemas internacionales del medio ambiente (VIII Jornadas de la Asociación Española de Profesores de Derecho Internacional y Relaciones Internacionales, Barcelona, 2 a 5 de julio de 1984), Barcelona, 1985, pág. 201 y ss.

${ }^{104}$ Cuarto informe sobre el derecho de los usos de los cursos de agua internacionales para fines distintos de la navegación (Doc. A/CN.4/412/Add. 1 y 2. 
Este instrumento, ha consagrado, en primer lugar - artículo $20^{105}$ - la obligación general de los Estados del curso de agua de proteger y preservar, individual o conjuntamente, los ecosistemas de los cursos de agua internacionales.

Asimismo se instituye en el artículo siguiente, la obligación de los Estados de prevenir, reducir y controlar, individual o conjuntamente, la contaminación de un curso de agua internacional que pueda causar daños sensibles - el Proyecto de la CDI, utilizó el término apreciables -, a otros Estados del curso de agua o a su medio ambiente, incluidos los daños a la salud o la seguridad humanas, a la utilización de las aguas con cualquier fin útil o a los recursos vivos del curso de agua (apartado 2), debiendo los Estados del curso de agua, a petición de cualquiera de ellos celebrar consultas para determinar ciertas medidas o métodos mutuamente aceptables para prevenir, reducir y controlar la contaminación de un curso de agua internacional (apartado 3).

Este mismo dispositivo -artículo 21-, incluye una definición de contaminación de un curso de agua, concebida como "toda alteración nociva de la composición o calidad de las aguas de un curso de agua internacional sea resultado directo o indirecto de un comportamiento humano"(apartado 1). Tal definición ha prescindido de la descripción del origen y de las consecuencias de la contaminación que incluían las definiciones propuestas por Schwbel, Evensen y McCaffrey. Ambos dispositivos guardan una estrecha vinculación y aparecen en la Convención como necesariamente interdependientes ${ }^{106}$ (282).

La Parte IV de la Convención se complementa con la obligación de los Estados del curso de agua de impedir la introducción en el curso de agua internacional de especies extrañas o nuevas que produzcan o puedan producir efectos nocivos en el ecosistema del curso de agua -artículo 22- y, artículo 23 - la obligación de los mismos Estados de proteger y preservar el medio marino, incluidos los estuarios, teniendo en cuenta las reglas y estándares internacionales generalmente aceptados. El término especies del artículo 22 comprende tanto la fauna como la flora y otros organismos vivos, y la expresión extrañas, se refiere a las que no son autóctonas.

El artículo 23, guarda estrecha relación con las disposiciones de la Convención de las Naciones Unidas sobre el Derecho del Mar de 1982, que ha establecido una regulación específica ${ }^{107}$. Se ha tenido en consideración el hecho de que cada vez con mayor frecuencia la contaminación del medio marino se produce por sustancias o residuos arrastrados por los cursos de agua, en este caso internacionales, con efectos devastadores en las especies ictícolas.

105 Los Estados del curso de agua protegerán y preservarán, individual y cuando proceda, conjuntamente, los ecosistemas de los cursos de agua internacionales.

106 TANZI,A. Y ARCARI, M.. Op.cit., pág. 237-271.

107 v. Parte XII, dedicada a la Protección y Preservación del Medio Marino y en particular el art. 207. 
Existe una relación directa entre las cuestiones examinadas precedentemente y las abordadas por la Convención en la Parte V, referida a las medidas para prevenir y mitigar las condiciones perjudiciales, y a las situaciones de emergencia. El artículo 27 instituye la obligación de los Estados del curso de agua de adoptar, individual o conjuntamente, las medidas apropiadas para prevenir o atenuar los efectos que resulten de causas naturales o de un comportamiento humano, que pudieran resultar perjudiciales para otros Estados del curso de agua. Tal es el caso de las crecidas o deshielos, enfermedades de origen hídrico, entarquinamiento, erosión, intrusión de agua salada, sequía o desertificación.

En relación a los casos o situaciones de emergencia, materia que regula el artículo 28 de la Convención, se ha definido a la situación de emergencia como

"la que cause graves daños a los Estados del curso de agua o a otros Estados, o cree un peligro inminente de causarlos, y que resulte súbitamente de causas naturales, como las crecidas, el deshielo, los desprendimientos de tierras o los terremotos, o de un comportamiento humano, como los accidentes industriales".

El dispositivo se complementa con las reglas procesales que imponen la obligación de la notificación sin demora a los demás Estados que pudieran resultar afectados y a las organizaciones internacionales competentes, cualquier situación de emergencia que sobrevenga en el territorio de un Estado, y con la obligación del Estado del curso de agua en cuyo territorio sobrevenga una situación de emergencia de adoptar las medidas posibles para prevenir, atenuar y eliminar los efectos nocivos, previéndose en su caso, la elaboración de planes conjuntos.

La Convención incluyó en la Parte IV, otros tres dispositivos referidos a la ordenación de los cursos de agua internacionales - artículo 24 , a la regulación de los mismos -artículo 25- y a las instalaciones - artículo 26 -, que también recogen ideas del Proyecto de la CDI, aunque con ligeras modificaciones, incluso terminológicas. Así, la CDI prefirió el concepto de gestión en vez de ordenación. La Convención incorporó una definición de ordenación que comprende "La planificación del aprovechamiento sostenible de un curso de agua internacional y la adopción de medidas para ejecutar los planes que se adopten", y "La promoción por cualquier otro medio de la utilización racional y óptima, la protección y el control del curso de agua". Se prevé la obligación de entablar consultas al respecto y, eventualmente, la creación de órganos de gestión. En cuanto a la regulación, por ella debe entenderse "la utilización de obras hidráulicas o cualquier otra medida estable para alterar, modificar o controlar de otro modo el caudal de las aguas de un curso de agua internacional". Se aplica el principio de cooperación y de la participación equitativa en la construcción y el mantenimiento o la financiación de las obras de regulación. Conforme al artículo 26, corresponde a los Estados del curso de agua, hacer lo posible para mantener y proteger las instalaciones, construcciones y obras ubicadas dentro de sus respectivos territorios, previéndose el procedimiento de 
consulta en el caso de que alguno de los estados tenga graves razones para creer que podría sufrir efectos perjudiciales sensibles por las instalaciones, construcciones u obras localizadas en otro Estado del curso de agua.

Este último artículo trata la cuestión de la protección de instalaciones tales como embalses, represas, diques o esclusas contra la acción deteriorante de las fuerzas naturales o de los actos humanos que pudieran ocasionar perjuicios sensibles a otros Estados del curso. El párrafo primero no pretende exigir a un Estado del curso de agua que mantenga o proteja obras en el territorio de otro Estado del curso de agua, aún cuando pueden darse casos en que resulte apropiado el mantenimiento y protección de obras situadas fuera de su territorio, si hubiera emprendido una explotación conjunta con el estado en que las obras estuvieren situadas. El párrafo segundo, contempla el caso en que un Estado del curso de agua esté convencido de la posibilidad real de un peligro determinado. Es una situación diferente a la de las situaciones de emergencia, que regula el artículo 28, dispositivo este último que exige un peligro inminente. El párrafo segundo del artículo 26 institucionaliza el derecho a entablar consultas sobre las instalaciones de que se trate ante actos de terrorismo, sabotaje o fuerzas como corrimientos de tierra o inundaciones. Este dispositivo sólo tiende a establecer pautas generales aplicables a la prevención de niveles básicos de protección de las obras vinculadas con los cursos de agua internacionales.

La Parte VI, contiene disposiciones diversas, vinculadas con la protección de los cursos de agua, instalaciones, construcciones y otras obras conexas en tiempo de conflicto armado internacional o no (artículo 29); a las obligaciones de los Estados del curso de agua caso de que pudieran surgir graves obstáculos para establecer contactos directos entre ellos (artículo 30); a los datos e informaciones vitales para la defensa y seguridad nacionales (artículo 31), cuestión esta a la que ya hicimos referencia; al principio de no discriminación (artículo 32), y a la solución de controversias (artículo 33 ).

El artículo 29 no ha consagrado ninguna norma nueva, sino que reitera el derecho internacional vigente para los conflictos armados internos e internacionales que contienen normas aplicables a los cursos de agua internacionales y a las obras vinculadas con ellos ${ }^{108}$.

De allí que el artículo 29 reitera normas vigentes tanto para los Estados del curso de agua como para terceros Estados, pues los cursos de agua internacionales y sus obras pueden ser utilizados o atacados por otros Estados en tiempo de conflictos armados. Es obvio que el dispositivo tiene una aplicación temporal limitada.

El artículo 32, consagra el principio de no discriminación, basada en la nacionalidad o la residencia para reconocer la libertad de acceso al

108 El art. 56 del Protocolo I, de 1977, adicional a los Convenios de Ginebra, ha establecido la protección de las presas, diques y otras obras que puedan producir la liberación de fuerzas peligrosas causando pérdidas importantes en la población civil. También existen referencias de otra índole aplicables al caso en los arts. 35, párrafo 3 y 55, párrafo 1 del mismo Protocolo. 
proceso judicial o de otra índole, de conformidad con sus ordenamientos jurídicos, a toda persona física o jurídica que haya sufrido daños apreciables a consecuencia de una actividad relacionada con un curso de agua internacional o que esté expuesta a un riesgo de sufrir tales daños.

El sentido del artículo, según la CDI, ha sido que cuando los Estados del curso de agua concedan acceso a los procedimientos judiciales o de otra naturaleza a sus nacionales o residentes, también debe habilitar tal acceso en pie de igualdad a los no nacionales y no residentes. El acceso es independiente de dónde se produzca o pueda producirse el daño ${ }^{109}$.

En relación a la cuestión de la solución de controversias, aunque había sido considerada por alguno de los Relatores Especiales, se la excluyó de los artículos aprobados en primera lectura en 1991 ${ }^{110}$. Sin embargo, por iniciativa de Rosenstock, desarrollada en sus dos informes ${ }^{111}$, esta materia fue incorporada en el Proyecto y luego en la Convención. El artículo 33, no ofrece mayores innovaciones en cuanto a los mecanismos usualmente aplicables, que van desde las negociaciones directas hasta los medios jurisdiccionales, como el arbitraje y el recurso a la Corte Internacional de Justicia. Se deja a salvo la vigencia de los acuerdos que pudieren haber establecido los Estados sobre el particular. El procedimiento arbitral ha sido regulado en un Apéndice.

El primer paso previsto para solucionar las controversias que pudieren originarse con motivo de la interpretación o aplicación de la Convención, según el apartado 2 del citado precepto, es el recurso a las negociaciones directas y si no se llegare a un acuerdo por este medio, se prevé los buenos oficios, la mediación, la conciliación y también el sometimiento a los mecanismos jurisdiccionales ya mencionados.

Igualmente, se ha previsto la constitución, de común acuerdo de una comisión de determinación de los hechos, que puede ser colegiada o unipersonal, cuya integración y procedimiento han sido regulados con cierta minuciosidad.

El artículo 33, prevé que al momento de ratificar, aceptar o aprobar la Convención o al adherirse a ella, o en cualquier momento posterior, las Partes que no sean una organización de integración económica regional, pueden emitir una declaración de aceptación obligatoria ipso facto y sin acuerdo especial en relación a cualquiera de las Partes que acepte la misma obligación, que la controversia sea sometida a la Corte Internacional de Justicia o a un tribunal arbitral ya establecido y en funcionamiento o a constituirse de conformidad con lo prescripto en el apéndice de la Convención. Para el caso de las organizaciones de integración económica regional, la declaración sólo puede referirse al arbitraje. En este último

\footnotetext{
109 Proyecto de informe. Op. cit., pág. 7-8. Existen numerosos convenios y recomendaciones de organizaciones internacionales que han consagrado este principio.

110 ONU, Asamblea General, Doc. A/CN.4/L, 463/Add.4, 5 de julio de 1991.

111 ONU, General Assembly, Doc. A/CN.4/451, 15 April 1993 y Doc. A/CN.4/462, 21 April, 1994.
} 
aspecto, la solución ha sido más coherente que la acogida en el Convenio de Helsinki, de 1992, ya examinado.

La Parte VII de la Convención contiene las cláusulas de rigor, referidas a la firma; a la ratificación, aceptación, aprobación o adhesión; a la entrada en vigor - para lo cual se requieren 35 instrumentos de ratificación, aceptación, aprobación o adhesión (artículo 36)-, y a los textos considerados auténticos.

Este instrumento ha merecido ya numerosos análisis y exámenes críticos, que ponen de manifiesto tanto los logros, como las omisiones y falencias.

A la fecha no ha entrado en vigor al no haber reunido el número de ratificaciones requeridas ${ }^{112}$.

\section{Régimen general}

\section{CANALES INTERNACIONALES ${ }^{113}$}

Según M. Sörensen ${ }^{114}$ los canales internacionales son vías acuáticas artificiales que conectan a varias partes de los mares navegables, que además permiten el paso de la navegación entre ellos.

Con estas simples palabras delimita con precisión las características de estos espacios sometidos a regímenes particulares.

En primer lugar que son vías de comunicación marítima. Los distingue así de los canales que unen cursos de agua internacionales, ya que éstos están sometidos a las normas específicas que acabamos de ver en el capítulo precedente.

En segundo lugar que comunican artificialmente dos mares, de lo que surge que se trata de canales marítimos con una situación totalmente distinta a la de los estrechos internacionales ${ }^{115}$, que a su vez se encuentran sometidos a las normas de Derecho del Mar.

El tercer elemento es que son vías de comunicación que facilitan la navegación en las grandes rutas internacionales.

Ahora bien, excluidos los canales fluviales y los estrechos, encontramos a los canales internacionales cuya condición jurídica no deriva del Derecho Internacional general sino de regímenes jurídicos particulares. Se excluye en consecuencia la existencia de una regla consuetudinaria que permita la libertad de navegación, sino que el régimen jurídico aplicable a cada uno de ellos es convencional ${ }^{116}$

\footnotetext{
$112 \mathrm{http} / / /$ treaties.un.org/Pages/ViewDetails.aspx?src=IND\&mtdsg no=XXVII-12\&chapter=27\&lang=en $9 \mathrm{de}$ marzo de 2.013.

${ }^{113}$ Este tema fue desarrollado por la Dra. Graciela R. Salas. Titular de Derecho Internacional Público. Universidad Nacional de Córdoba.

${ }^{114}$ SÖRENSEN, MAX. Manual de Derecho Internacional Público. Fondo de Cultura Económica. México. 1985, pág. 330.

${ }^{115}$ Más allá de su denominación encontramos canales como el Canal de la Mancha, el Canal de Mozambique o el Canal de Beagle, que no son artificiales sino accidentes naturales, por lo que no se incluyen en este punto ya que se les aplica el régimen establecido en el Derecho del Mar.

116 T.P.J.I. caso del Wimbledon, sobre el Canal de Kiel. Disponible en: http://www.icjcij.org/pcij/serie_A/A_01/03_Wimbledon_Arret_08_1923.pdf 5 de marzo de 2.013.
} 
En punto a la soberanía es indiscutido que el Estado ribereño la conserva sobre estos canales internacionales y en consecuencia es quien regula su funcionamiento. Sin embargo, constituyendo medios de comunicación de extraordinaria importancia, quedan sometidos a un régimen de internacionalización que impone al Estado territorial ciertas obligaciones con el objetivo es facilitar el paso de los navíos extranjeros.

Los canales existentes actualmente y que responden a estas características, actualmente son: Canal de Suez (África), Canal de Kiel (Europa) ${ }^{117}$, Canal de Panamá (América).

\section{Canal de Suez.}

Con una extensión de 160 kilómetros, fue construido en territorio egipcio por la empresa francesa privada dirigida por Fernando de Lesseps e inaugurado en 1869.

En los primeros tiempos no tuvo una reglamentación particular, pero luego de la guerra ruso-turca de 1877 y problemas internos en Egipto en 1881 se hizo necesaria su reglamentación. Esto se logró con el Convenio de Constantinopla de $1888^{118}$ que estableció tres principios básicos: a) libertad de navegación comercial en todo tiempo; b) libertad de paso para los barcos de guerra a condición de que no se detengan ni desembarquen tropas ni materiales en él; c) neutralización del canal, en tiempos de paz y en tiempos de guerra.

Su funcionamiento se vio afectado por acciones bélicas durante la Gran Guerra, y durante la Segunda Guerra Mundial fue atacado por fuerzas del Eje. Terminada esta conflagración y hasta 1956 el funcionamiento de este canal también se vio afectado por las reivindicaciones egipcias contra las tropas inglesas instaladas en la región y por el control de la Compañía del Canal de Suez que lo administraba, por parte de Francia y Gran Bretaña. Asimismo se vio afectado por las controversias entre Egipto y sus vecinos, y por la situación en Palestina.

En 1956, poco antes de la segunda guerra árabe-israelí, Egipto nacionalizó la Compañía Universal del canal de Suez. A partir de entonces el canal fue administrado por Gamal Abdel Nasser hasta su cierre en 1967 cuando estallaron las hostilidades entre Egipto e Israel en la llamada Guerra de los Seis Días. El cierre del canal se produjo nuevamente como en 1956, por el bloqueo provocado por el hundimiento de varios barcos dentro del canal.

Se reabrió en junio de 1975, permaneciendo desde entonces abierto al tráfico internacional. En 1979 se celebraron los Acuerdos de Camp David entre Egipto e Israel en los que ambas partes reconocen la aplicabilidad a Israel del Convenio de Constantinopla de 1888 .

\section{Canal de Kiel}

Con una extensión de 98 kilómetros, fue inaugurado en 1895 por el Kaiser alemán Guillermo II.

\footnotetext{
${ }^{117}$ El primero une al Mar Rojo con el Mar Mediterráneo, el segundo al Mar Báltico con el Mar del Norte, el último une el Mar del Caribe con el Pacífico.

118 Firmada por Reino Unido, Francia, Alemania, Rusia, Turquía, Austria-Hungría, España, Países Bajos e Italia. Su texto está disponible en http://bdigital.binal.ac.pa/bdp/canalpanama3.pdf 11 de marzo de 2.013
} 
Fue internacionalizado después de la Primera Guerra Mundial por el Tratado de Versalles quedando abierto a todos los buques de comercio y guerra que estuvieren en paz con Alemania, y bajo administración germana. La navegación por este canal llevó al pronunciamiento del T.P.J.I. en el caso del vapor Wimbledon (1923), ya citado.

Alemania anuló ese status internacional en 1936 al denunciar Alemania el Tratado de Versalles y en 1945, al finalizar el conflicto armado. Luego de la derrota sufrida por Alemania durante la Segunda Guerra Mundial el canal quedó reabierto a todo tipo de tráfico.

Actualmente se encuentra abierto a toda embarcación, aunque con ciertas restricciones establecidas por Alemania, para el uso de naves de grandes dimensiones como portaaviones o grandes petroleros.

\section{Canal de Panamá}

Con una extensión de 1432 kilómetros, fue construido por EEUU sobre territorio panameño e inaugurado en 1914.

La construcción de este canal se logró al celebrarse el tratado Hay- Bunau-Varilla (1903) por el cual se otorgaba a EEUU, a perpetuidad, el control de la llamada zona del canal, haciéndose cargo de la construcción del canal, su mantenimiento y defensa militar.

El régimen amplio establecido originariamente fue reduciéndose por medio de acuerdos como el tratado del 3 de marzo de 1936 a partir del cual se estableció la defensa común del canal; el tratado del 25 de enero de 1955 que otorgó a Panamá derechos de tasas a los que antes había renunciado y restringió privilegios a los residentes norteamericanos de la zona.

Como consecuencia del proyecto de Resolución del Consejo de Seguridad de las Naciones Unidas de 1973, en 1974 se iniciaron negociaciones entre ambas partes que concluyeron con el Tratado Carter-Torrijos de 1977. Por este acuerdo se reconoce la soberanía territorial de Panamá, previendo un régimen de protección y defensa común entre ambas partes hasta el 31 de diciembre de 1999. Fue en esa fecha que la República de Panamá recuperó la plenitud de soberanía sobre este canal, en las condiciones establecidas por ambas partes.

Este tratado a su vez está constituido por varios acuerdos.

En definitiva se resuelve sobre la neutralidad perpetua del canal y el funcionamiento del Canal de Panamá, por su importancia no sólo como vía de comunicación sino para la paz y seguridad del hemisferio occidental. En este tratado se declara al canal como "vía acuática de tránsito internacional permanentemente neutral "(artículo 1), en un pie de igualdad para el tránsito pacífico de naves de todas las banderas, incluso en caso de guerra.

Según la Constitución Nacional de Panamá"119 (Título XIV), "constituye un patrimonio inalienable de la Nación panameña; permanecerá abierto al tránsito pacifico e ininterrumpido de las naves de todas las naciones y su uso estará sujeto a los requisitos y condiciones que establezcan esta Constitución, la Ley y su Administración".

El funcionamiento y la administración del Canal de Panamá se encuentran bajo la responsabilidad de la Autoridad del Canal de Panamá a cargo de una Junta Directiva

\footnotetext{
${ }^{119}$ Disponible en:

http://www.asamblea.gob.pa/main/LinkClick.aspx?fileticket=fDgmRvYW8cY\%3D\&tabid=123 Consultado el 12 de marzo de 2.013 .
} 
compuesta por once directores, todos ellos panameños, con arreglo a lo establecido por la Constitución Política de la República de Panamá.

Bibliografía

ALVARADO GARAICOA, T. La trascendencia del descubrimiento del Río de las Amazonas, en Estudios de Derecho Internacional Público y Privado - Homenaje al Prof. Luis Sela Sampil, Oviedo, España.

ARMAS BAREA, C. Primeras Jornadas Universitarias sobre Integración Latinoamericana y Desarrollo de la Cuenca del Plata, Córdoba (Argentina), 1968.

AZCÁRRAGA, J. L. DE. Derecho Internacional Marítimo, Barcelona, 1970.

BARBERIS, JULIO A. Droits et obligations des pays riverains des fleuves internationaux, Acadèmie de Droit International de La Haye, Dordrecht, 1991

BARBERIS, JULIO. Los recursos naturales compartidos entre Estados y el Derecho Internacional, Madrid, 1979.

BARBERIS, JULIO. Principios jurídicos que regulan la libre navegación en la Cuenca del Plata, en Ríos y Canales navegables internacionales, UNITAR, Buenos Aires, 1971.

BRIERLY, J.L. Régles Génèrales du Droit de la Paix, en RCADI.,Vol. 58,1936-IV. La diversidad de situaciones que engendran los ríos internacionales que hace impracticable una uniformización a ultranza ha sido señala también por De Visscher, C. (Cf. Cours Général de Principes de Droit International Public, en RCADI, Vol. 86, 1954-II

CAICEDO CASTILLA, J. La obra del Comité Jurídico Interamericano", Río de Janeiro, 1966.

CALVO Y PEREYRA, M. De las aguas tratadas desde el punto de vista legal, Madrid, 1862.

CARDONA LLORENS, J. La protección del medio ambiente de los cursos de agua internacionales en los trabajos de la Comisión de Derecho Internacional, en Problemas internacionales del medio ambiente (VIII Jornadas de la Asociación Española de Profesores de Derecho Internacional y Relaciones Internacionales, Barcelona, 2 a 5 de julio de 1984), Barcelona, 1985.

CARDONA, S. El régimen jurídico de los ríos internacionales, en Revista de Derecho Internacional Público (La Habana), Año XXVIII, T. LVI

CASTILlO DAUDI, M. La protección y preservación de cursos de agua internacionales: el Convenio sobre el derecho de los usos de los cursos de agua internacionales para fines distintos de la navegación de 21 de mayo de 1997, en Anuario de Derecho Internacional, Universidad de Navarra, Vol. XV, 1999

CHIESA, N.E. Regulación Jurídica del Aprovechamiento Hidroeléctrico de Ríos Internacionales, Documento de Trabajo presentado en el Primer Congreso Ordinario de la Asociación Argentina de Derecho Internacional, 
Mendoza (Argentina), marzo de 1971, y La problemática estructural, técnica y jurídico-institucional del aprovechamiento compartido del recurso hidroeléctrico internacional (No marítimo).

CHIESA, N. E. La protección del medio ambiente y el derecho internacional, en Revista de Derecho Internacional y Ciencias Diplomáticas, Rosario (Argentina), No. 46-47, 1977-1978. Y "Cuestión ambiental: derecho y política internacional", en Revista de Derecho Internacional y Ciencias Diplomáticas, Rosario (Argentina), No. 48-49, 1979-1980.

COLOMBOS J. Derecho Internacional Marítimo, Madrid, 1961.

DE VISSCHER P. Ob. Teoría y Realidades en Derecho Internacional Público (Trad. de Sancho Riera), Barcelona, 1964. En "Cours Général de Principes de Droit International Public", RCADI, Vol. 86, 1954-II.

DIEZ DE VELASCO VALLEJO, MANUEL. Instituciones de Derecho Internacional Público, Madrid, T. I, 6 ${ }^{\mathrm{a}} \mathrm{Ed}$.

DIEZ DE VELASCO VALLEJO, MANUEL. Instituciones de Derecho Internacional Público, Madrid. 2018. $18^{\circ} \mathrm{Ed}$.

GONZÁLEZ CAMPOS, JULIO D., SÁNCHEZ RODRÍGUEZ, LUIS I., PAZ ANDRÉS SÁENZ DE SANTAMARÍA. Curso de Derecho Internacional Público. Thomson Civitas. Madrid. 2003.

GUNTHER HANDL. International Liability for the Pollution of International Watercourses: Balancing Interests, en Canadian Yearbook of International Law, Vol. XIII, 1975.

JIMENEZ DE ARECHAGA, E. El Derecho Internacional Contemporáneo, Madrid, 1980.

KAUFMANN. Règles Génèrales du Droit de la Paix, en RCADI, Vol. 54, 1935 -IV.

NAVARRO VEGA, I. La contaminación de los ríos internacionales, en Estudios sobre Derecho Internacional, Asociación Mexicana de Derecho Internacional, México, 1975.

ROUSSEAU, CHARLES. Derecho Internacional Público. Ariel. Barcelona. 1966.

SÖRENSEN, MAX. Manual de Derecho Internacional Público. Fondo de Cultura Económica. México. 1985.

MARTÍNEZ-AGULLÓ Y SANCHIS, LUIS. Los tratados y la costumbre en el derecho fluvial internacional, en Revista Española de Derecho Internacional, Vol. XV, $\mathrm{N}^{\mathrm{o}}$ 1-2, 1962.

OPPENHEIM, M. A. Tratado de Derecho Internacional Público, Trad. de López Olivan, Barcelona, 1961.

RAUX, J. Régionalisation et centralisation en matière d'administration fluviale, en RGDIP, T. 73, 1969.

REUTER, P. Derecho Internacional Público, (Trad. de Truyol y Serra), Barcelona, 1962.

REY CARO, ERNESTO J. El derecho de los usos de los cursos de agua internacionales en los trabajos de la Comisión de Derecho Internacional, en Revista Española de Derecho Internacional, Vol. XXXI, N 1-3, 1978. 
REY CARO, E. J. Derecho Internacional Ambiental, en Estudios de Derecho Internacional, Córdoba (Argentina), 1982

REY CARO, ERNESTO J. Regulación jurídica del aprovechamiento de los cursos de agua internacionales, en Jurisprudencia Argentina, Bs. As., junio 8 de 1977.

REY CARO, ERNESTO J. La consulta previa en el aprovechamiento de los recursos naturales compartidos. Los ríos internacionales, en Cuadernos de Derecho Público de la Universidad de los Andes, $\mathrm{N}^{\circ} 4,1978$

ROUSSEAU, CHARLES. Droit International Public, París, 1977.

RUIZ MORENO, I. El aprovechamiento de los ríos internacionales en América, en Estudios de Derecho Internacional Público, Buenos Aires, 1965.

TANZI, A. Y ARCARI, M. The United Nations Conventions on the Law of International Watercourses. A Framework for Sharing, Kluger Law International, 2001. 